\title{
LA PREHISTORIA DE IBIZA Y FORMENTERA: ESTADO ACTUAL DE LA INVESTIGACION
}

\author{
A. C. Topp
}

\author{
POR \\ CARLOS GOMEZ BELLARD (") \\ MARIA PILAR SAN NICOLAS PEDRAZ $(*)$
}

RESUMEN El estudio de la Prehistoria de Ibiza y Formentera, que forman el subgrupo de las Pitiusas dentro del archipiélago balear, se inició hace pocos años a raíz del descubrimiento y excavación del sepulcro megalítico de $\mathrm{Ca}$ Na Costa en Formentera, ya que hasta entonces se dudaba todavía de la presencia humana en esas islas antes de la colonización fenicia. En poco más de una década se han conocido numerosos yacimientos que permiten intentar por primera vez un acercamiento global al tema. Sin embargo son todavía muchos los problemas que subsisten y sólo nuevas excavaciones conducirán al establecimiento de una secuencia cultural aparentemente compleja que por lo que hoy sabemos se inicia en la primera mitad del II milenio.

ABSTRACT The study of the prehistory of Ibiza and Formentera, the two small islands that form the Pityussae sub-group within the Balearic archipelago, began a few years ago as a consequence of the discovery and excavation of the megalithic chamber tomb of a Ca $\mathrm{Na}$ Costa on Formentera. Before then, prehistorians were still in doubt as to whether these islands had been occupied before the Phoenician colonisation. Many sites have come to light in the last decade, allowing us to present for the first time a general survey of the prehistoric settlement of the islands. Nevertheless, many problems are still unsolved, and new excavations are needed to establish the apparently complex cultural sequence, which seems to have begun in the first half of the second millennium.

Palabras clave: Prehistoria. Ibiza. Formentera. Megalitismo. Depósitos de bronce.

La ocupación humana pre-fenicia de Ibiza y Formentera ha sido uno de los problemas arqueológicos que no se han podido resolver - al menos en parte- hasta hace pocos años. En su siempre citada e imprescindible obra, Tarradell y Font dedicaban en 1975 un capítulo a repasar el estado de la cuestión, titulado significativamente "L'enigma del poblament d'Eivissa i de Formentera abans dels cartaginesos". Dichos autores eran relativamente pesimistas en cuanto a la posibilidad de conocer la prehistoria de las islas, dada la parquedad de los hallazgos realizados hasta entonces,

(") (Profesor de Prehistoria y Arqueología de la Universidad de Valencia).

(“) (Departamento de Arqueología del Consejo Superior de Investigaciones Cientificas). 
consistentes, sobre todo, en diversos tipos de hachas de bronce. Una esperanza se apuntaba sin embargo, las posibilidades que abria el hallazgo, entonces recientisimo, de una tumba megalítica en Formentera, cuya excavación podria empezar a iluminar ese oscuro periodo de la historia isleña (Tarradell-Font, 1975: 225-231)

En los diez años transcurridos desde entonces, y a raiz de los magnificos resultados obtenidos en el sepulcro megalítico de $\mathrm{Ca} \mathrm{Na}$ Costa, se han multiplicado los estudios, las excavaciones, etc..., pudiéndose ya hablar de una prehistoria de las Pitiusas, frente a la opinión de gran número de cualificados autores que consideraron que Ibiza y Formentera habrian estado probablemente deshabitadas al menos hasta la llegada de los cartagineses en el s. VII a. J.C. (García y Bellido, 1952: 339; Childe, 1957: 263-264; Daniel, 1958: 87; Almagro, 1960: 656).

Hemos de matizar, sin embargo, las líneas que anteceden. Indudablemente existió una presencia humana anterior a la instalación fenicia, como veremos más adelante a través del estudio pormenorizado de excavaciones y hallazgos. Se han obtenido algunas dataciones absolutas y se han reestudiado materiales aparecidos desde principios de siglo, situándolos cronológicamente con bastante precisión. Pero no se ha podido establecer una secuencia cultural continua, de manera que nos encontramos ante dos fases prehistóricas, una relativamente bien conocida, en torno al 1500 a. J.C., y otra menos clara en los siglos VIII-VII a. J.C., pero sin apenas elementos que permitan llenar los siglos intermedios, en realidad casi un milenio. Esto supone un gran problema, pues queda aún por resolver la cuestión de la población indigena de las islas en el momento de la llegada de los primeros comerciantes y marinos fenicios y de su asentamiento en la bahía de Ibiza.

Para aclarar dicha cuestión y establecer el estado actual de los conocimientos, repasamos todos los yacimientos y materiales prehistóricos conocidos de ambas islas (Fig. 1), intentando situarlos en una secuencia cronológica (véase cuadro I). No incluimos la historia de la investigación, que complicaría innecesariamente la exposición, y que además puede encontrarse en los diversos artículos que citamos.

\section{EL SEPULCRO MEGALITICO DE CA NA COSTA (FORMENTERA) (Lám. I, a)}

Es, sin lugar a dudas, el monumento más interesante de la prehistoria pitiusa, no sólo por su buena conservación sino también por su originalidad. Se encuentra al norte de la isla, a poco más de $1 \mathrm{~km}$. de Es Pujols, sobre una pequeña lengua de tierra que se adentra en S'Estany Pudent, una de las dos albuferas formenterenses. Fue excavado en 1974 y 1977, pubicándose rápidamente y en varias ocasiones dado su enorme interés (Fernández, Plantalamor, Topp, 1976; Topp, Fernández, Plantalamor, 1976, 1979; Fernández, 1977, 1984; Fernández, Topp, 1984).

Se trata de un sepulcro de planta circular (Fig. 2), sin ningún tipo de elaboración compleja o añadidos como cámaras laterales, nichos, etc... Hecho de piedra calcárea, se compone de un pequeño espacio enlosado, un corredor corto y una cámara circular a la que se accede por una losa perforada mal conservada. El atrio mide 2,05 por 1,30 m., y está ligeramente en alto respecto al corredor. Este, que está a nivel de la roca, se abre exactamente hacia el 0 . Mide 2,5 m. y está formado por cuatro ortostatos emparejados, dispuestos de manera que el pasadizo resulta más ancho y alto a medida que se acerca a la cámara. Esta está compuesta por siete ortostatos fijados en una hendidura circular poco profunda hecha en la roca madre, falcados por piedras más pequeñas. Tiene un diámetro medio de $3,60 \mathrm{~m}$. y los grandes bloques alcanzan los $2 \mathrm{~m}$., con un espesor de $0,35 \mathrm{~m}$. Posiblemente la cubierta fuese de material perecedero, vigas, ramas y tierra apisonada. Rodeando los elementos descritos hay tres muros de retención, interrumpidos por el corredor y el patio, hechos para afianzar los bloques de la cámara. El muro interno conserva tres hiladas de piedras de tamaño medio, y el espacio entre éstas y la cámara había sido rellenado de 

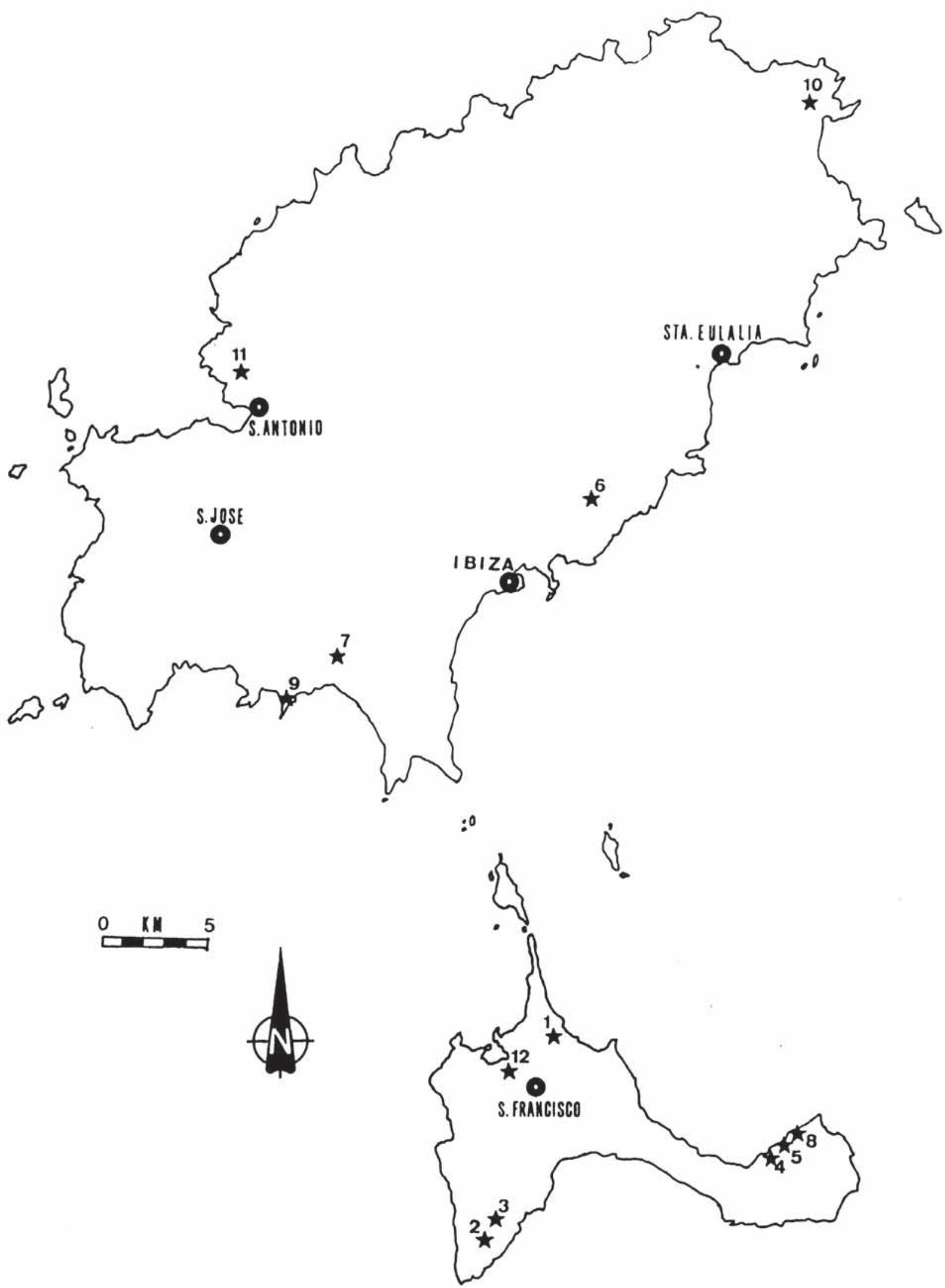

Fig. 1.- Principales yacimientos de Ibiza y Formentera mencionados en el texto: 1. Ca Na Costa. 2. Círculos del Cap de Berbería. 3. Poblado del Cap de Berberia 4. Cova des Fum. 5. Cova des Riuets. 6. Cova Xives. 7. Can Sargent. 8. Sa Cala. 9. Puig Jondal. 10. Es Cuieram. 11. Ses Fontanelles. 12. Portusalé. 


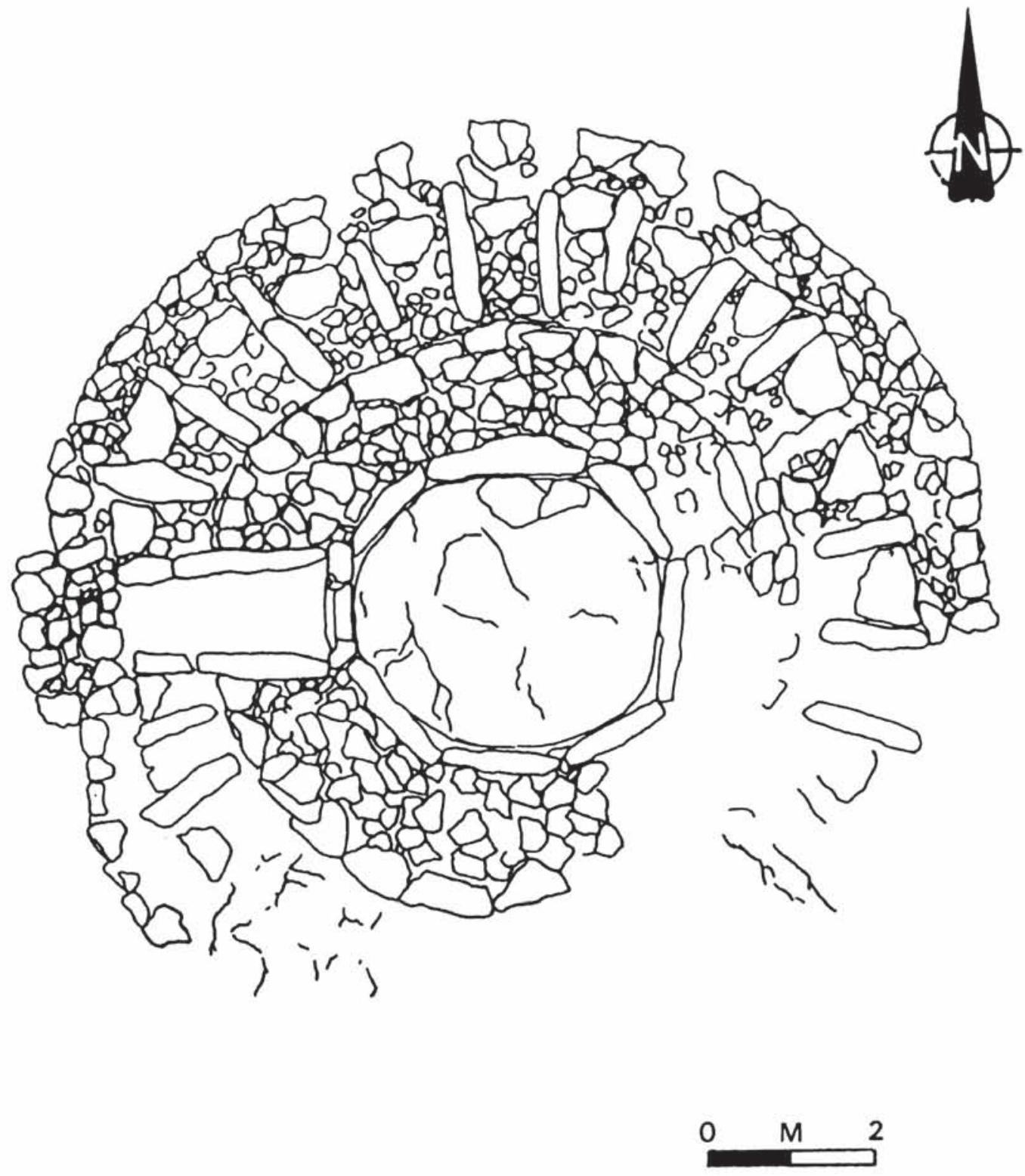

Fic. 2.- Planta del sepulcro megalítico de Ca Na Costa, en Formentera (según Topp et alii, 1976).

piedra menuda y tierra. Este muro estaba reforzado por 24 grandes bloques a manera de contrafuertes, colocados en sendas hendiduras hechas en la roca y dispuestos radialmente, de los que se conservan 14 in situ, siendo evidentes las marcas de otros cuatro. Estos refuerzos simétricamente distribuidos constituyen, hoy por hoy, un caso poco frecuente entre las tumbas megalíticas, y el único paralelo que se ha podido encontrar es el del sepulcro de Mas Plá, en Querol (Tarragona). La cámara fue excavada en los años 60 (Maluquer et alii, 1963), pero trabajos más recientes han permitido sacar a la luz la cuarta parte del túmulo, comprobándose la existencia de unos contrafuertes radiales, con espacios intermedios rellenos de piedras medianas y grandes (Mestres, 1982).

$\mathrm{El}$ espacio entre los contrafuertes fue rellenado en $\mathrm{Ca} \mathrm{Na}$ Costa con piedra menuda y tierra. En cuanto al tercer muro, es muy semejante al primero.

Los hallazgos no fueron muy abundantes: fragmentos cerámicos muy pequeños de formas abiertas, globulares, troncocónicas y bitroncocónicas, dos de ellos incisos (Fig. 3), un brazalete de arquero 

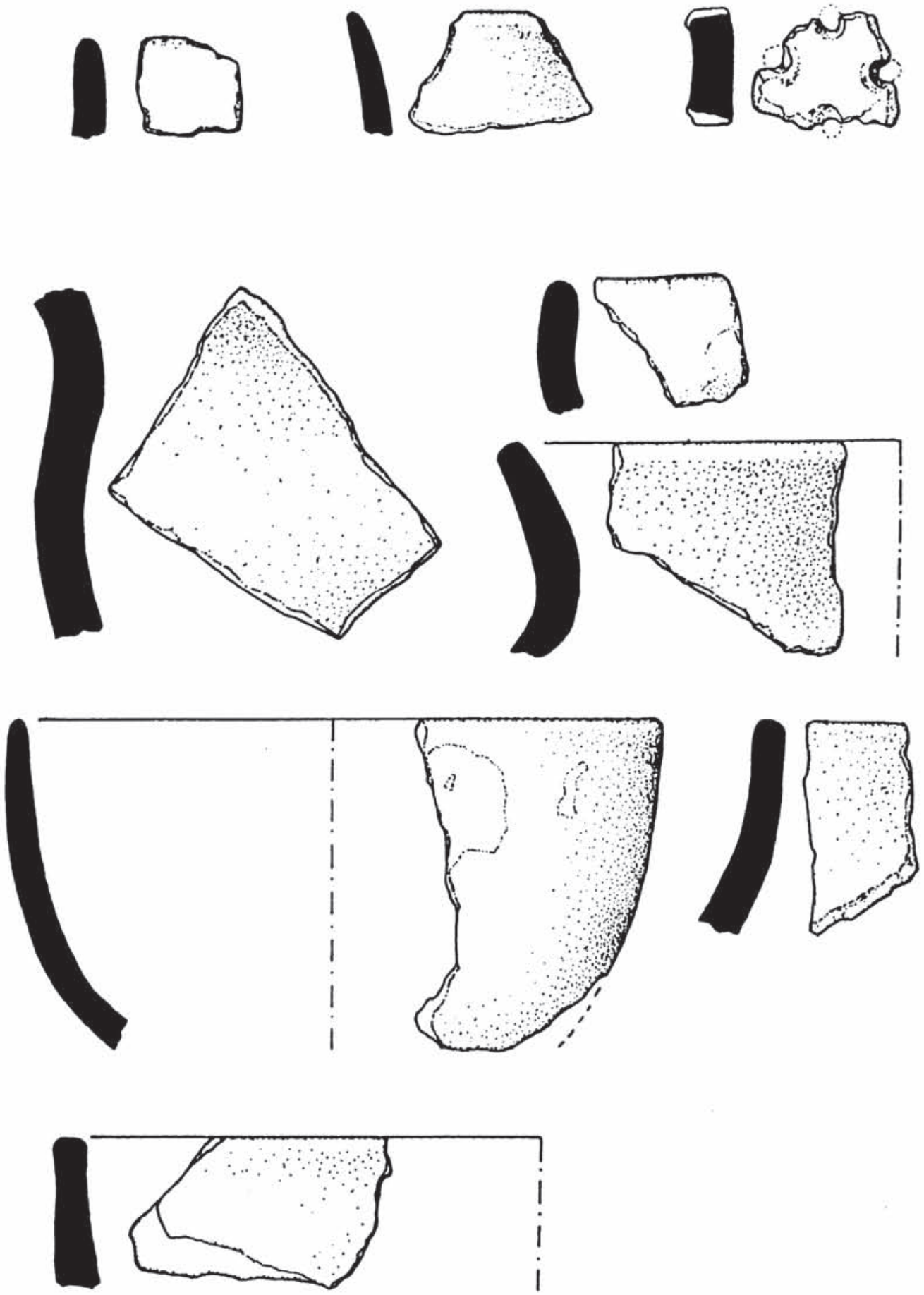

0 5

Fig. 3.- Fragmentos cerámicos de Ca Na Costa (según Topp et alii, 1976). 
incompleto (Fig. 4), dos pequeñas cuentas de collar circulares y sobre todo 13 botones de perforación en $\mathrm{V}$ completos y dos fragmentarios de hueso (Fig. 5). Todo ello unido al hallazgo de tres fragmentos de sílex (los primeros de las Pitiusas), dos de ellos trabajados, y la total ausencia de metal llevó a los excavadores proponer en una primera publicación una fecha de 2000-1600 a. J.C. (Topp et alii, 1976: 171). Dicha datación se ha visto confirmada gracias al análisis de C14 de los restos humanos encontrados en la cámara.

$$
\text { BM }-1677 \quad 1600 \pm 80 \text { B.C. }=1320 \pm 80 \text { b.c. }
$$
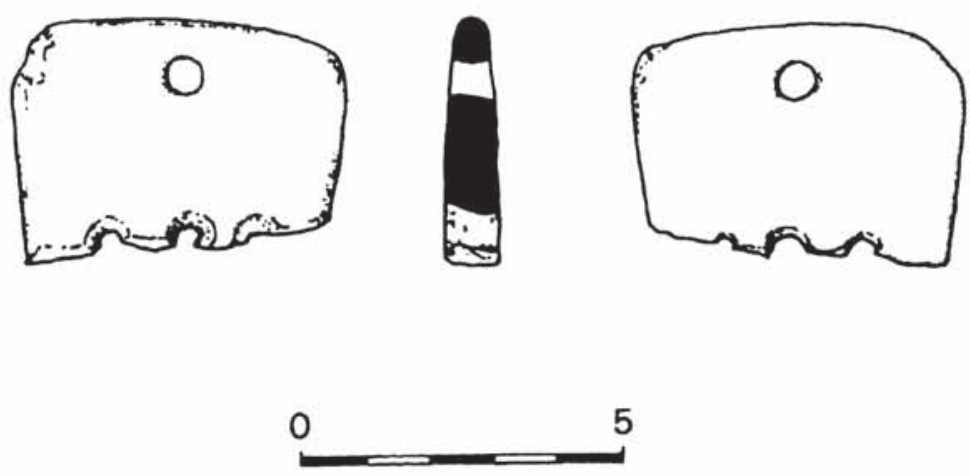

FIG. 4.- Fragmento de «brazalete de arquero de Ca Na Costa (según Topp et alii, 1979).
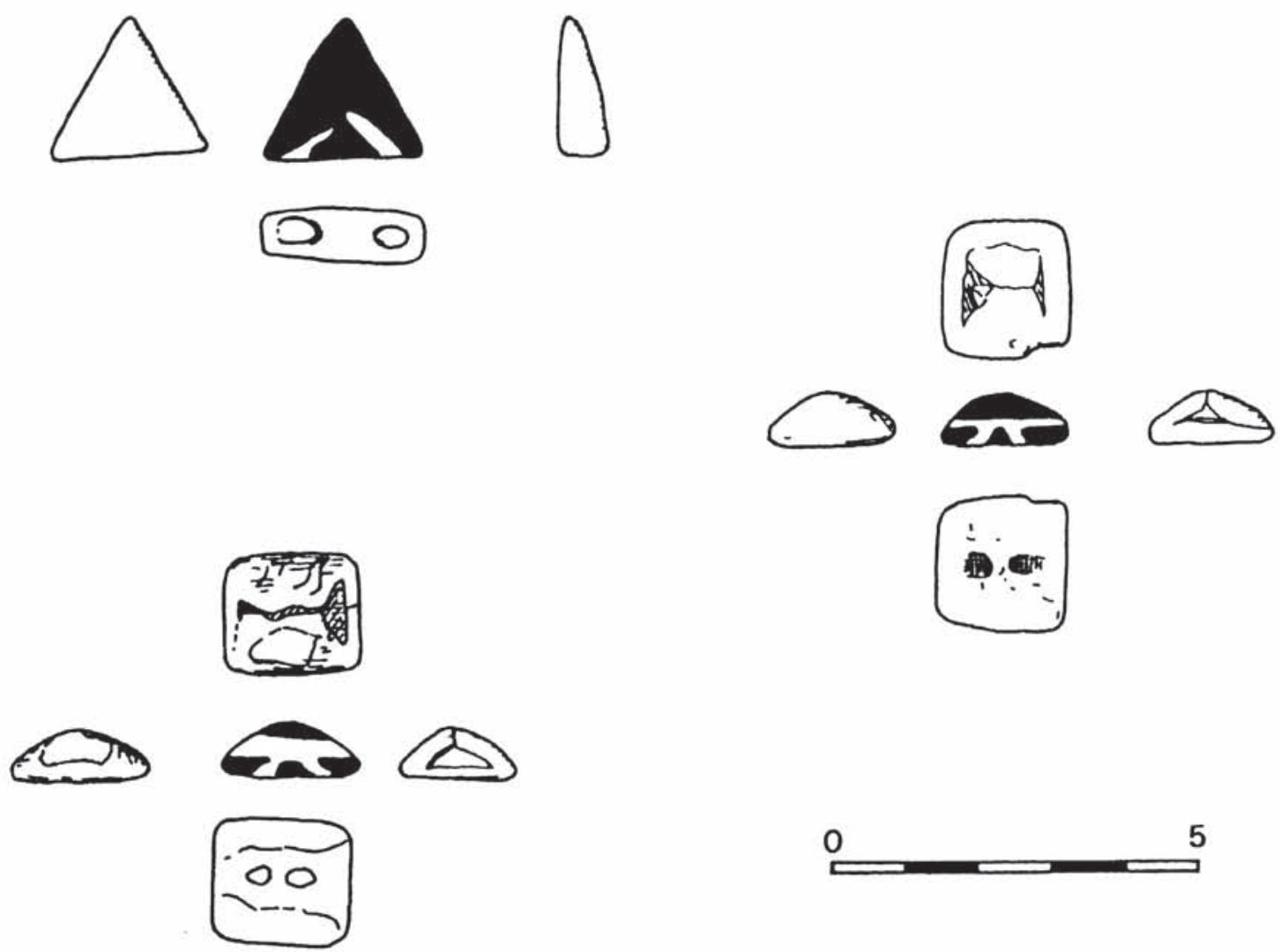

5

Fig. 5.-Botones de perforación en V de Ca Na Costa (segün Topp et alii, 1976). 


\section{EL POBLADO Y LOS CIRCULOS DEL CAP DE BERBERIA (FORMENTERA) (Lam. I, b)}

Como consecuencia del hallazgo y excavación de $\mathrm{Ca} \mathrm{Na}$ Costa, la investigación se desplazó hacia el sur de Formentera, en la zona denominada Es Cap de Berbería y más concretamente Es Pla del Rei. Había algunas indicaciones antiguas, como las de Jose M. ${ }^{a}$ Mañá, director del M.A.I. de 1944 a 1964, que hacían referencia a la existencia allí de «... hitos o piedras verticales dispuestas en círculos que... presentan características que recuerdan las citanias del noroeste peninsular, la de Briteiros más concretamente" (Mañá, 1952: 14). Por desgracia, Mañá no llegó a ver esos círculos, y a principios de los años sesenta fueron arrasados para usar la piedra en la construcción de la carretera que lleva al faro del Cap.

A pesar del pésimo estado de conservación, se han realizado varias excavaciones en diversos puntos, con la esperanza de atestiguar la existencia de lugares de hábitat relacionables cronológicamente con $\mathrm{Ca} \mathrm{Na}$ Costa. La mayor parte de los resultados permanecen inéditos, habiéndose publicado únicamente algunas breves notas (Topp et alii, 1979; Fernández, 1984).

De los numerosos círculos de piedras existentes (Gordillo, 1981: 54), se han excavado dos en extensión. El primero, en 1976, tiene $13 \mathrm{~m}$. de diámetro y se conserva, en alguna zona muy reducida, hasta $1,10 \mathrm{~m}$. de altura. Dentro de él, separado por $0,50 \mathrm{~m}$., hay otro círculo (puede tratarse de los dos parámetros de un mismo muro) que se subdivide en varias habitaciones circulares u ovales, dejando un área central despejada. La posible entrada estaría en el lado sur, pero todo el tercio norte está totalmente arrasado, lo que impide el conocimiento completo de la estructura (Fig. 6). La escasez de los hallazgos, apenas unos fragmentos amorfos y de un fragmento con asa horizontal, dificulta una posible adscripción cronológica, aunque el claro paralelismo de las estructuras con el poblado que veremos más adelante permite suponer que son contemporáneos. La misma ausencia de cerámicas u otros objetos induce a pensar que difícilmente puede tratarse de un lugar de hábitat, sino más bien de alguna sencilla estructura destinada a guardar ganado.

El círculo B del Cap de Berbería se encuentra junto a la carretera del Cap, a la altura del km. 4. Fue excavado en 1982 y se presenta como una estructura circular de $6 \mathrm{~m}$. de diámetro; muy arrasada, por desgracia, sólo conserva alguna piedra con $0,70 \mathrm{~m}$. de altura. No proporcionó material alguno (1).

Resultados mucho más interesantes está proporcionando el llamado Poblado del Cap, situado a unos $500 \mathrm{~m}$. del círculo A y a unos $200 \mathrm{~m}$. del círculo B. En él se han realizado ya tres campañas de excavaciones.

Se trata de una gran área de unos $1.500 \mathrm{~m}^{2}$ cubierta de estructuras ovales y circulares que se cruzan, permitiendo distinguir claramente algunas habitaciones. Los principales hallazgos son una gran cantidad de cerámica, fina, decorada y con asas de botón perforado, así como un "brazalete de arquero" incompleto, todo ello muy semejante a lo encontrado en $\mathrm{Ca} \mathrm{Na}$ Costa. Si el C14 que se está realizando lo confirma, no cabe duda de que estaríamos ante las estructuras de hábitat contemporáneas a las gentes que erigieron el citado sepulcro (Fernández-Topp, 1984: 767).

\section{LOS HABITATS EN CUEVAS: COVA D'ES FUM, COVA DES RIUETS Y COVA XIVES}

Situadas las dos primeras en Formentera y la otra en Ibiza, estas tres cuevas naturales han proporcionado - siempre a nivel de prospección- algunos interesantísimos materiales cerámicos

(1) Agradecemos a don Jorge H. Fernández y a doña Celia Topp los datos facilitados sobre esta excavación, todavía inédita. 


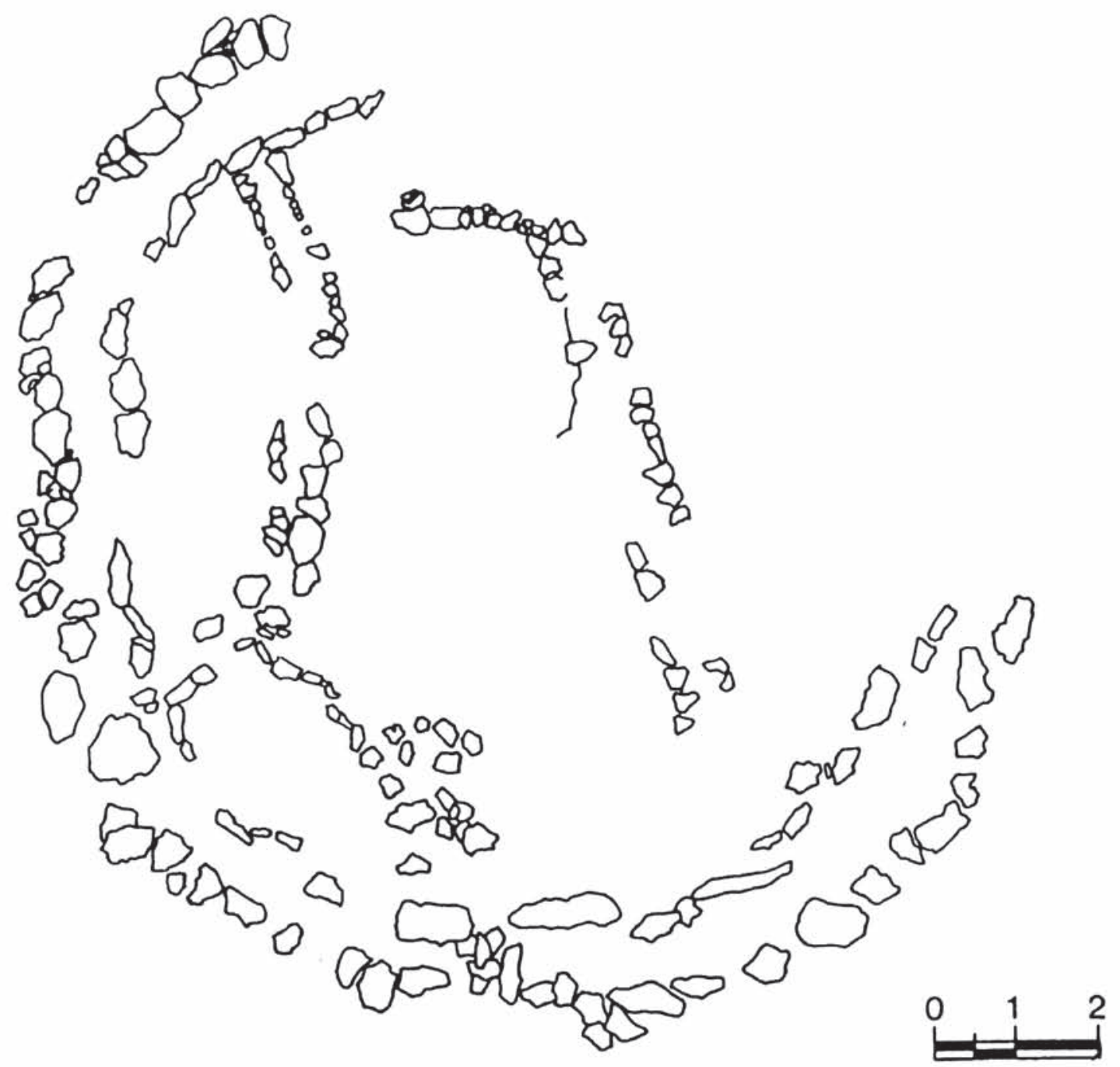

Fig. 6.-Planta del Círculo A del Cap de Berberia, en Formentera (según Topp et alii, 1979).

que han permitido suponer su utilización como lugar de hábitat, en un época situable en torno a la mitad del segundo milenio a. J.C. Desgraciadamente ninguna de ellas ha podido ser excavada científicamente todavía, y las dataciones que se han propuesto, salvo en el primer caso, lo han sido por comparación con las cerámicas bien fechadas de $\mathrm{Ca} \mathrm{Na}$ Costa.

La Cova d'Es Fum es una de las muchas que se abren en los acantilados del norte de la Mola, en el este de la isla. No es de fácil acceso actualmente y tiene un emplazamiento estratégico: se abre a $50 \mathrm{~m}$. sobre el nivel del mar en un acantilado de algo más de $90 \mathrm{~m}$. de altura, y no es visible ni desde arriba, ni desde el mar, camuflada además su boca de entrada por un muro de piedras de cierto tamaño. Sus múltiples galerías interiores, a diversos niveles, suponen no menos de $8.000 \mathrm{~m}^{2}$ que fueron utilizados en diferentes épocas. De las diversas prospecciones realizadas por J. L. Gordillo Courcières a lo largo de los últimos años (tuvimos oportunidad de acompañarle en memorable ocasión en 1980) proceden centenares de fragmentos cerámicos de época prehistórica y, sobre todo, musulmana, materiales aún por estudiar. También al parecer proceden de esta cueva un pequeño cuenco casi completo y tres fragmentos de cerámica con decoración incisa de gran calidad, entregados al M.A.I. en 1983 por un particular. Recientemente estudiadas por C. Topp, su próxima publicación permitirá ampliar al ámbito de las Pitiusas el problema planteado por las 
cerámicas incisas mallorquinas y la supuesta existencia de la cultura campaniforme en las islas (Cantarellas, 1972: 78-79; Waldren, 1985).

La Cova des Riuets se encuentra a poca distancia de la d'Es Fum, algo más al este, y forma junto con otras dos (Cova de Sa Fresca y Mamelles) el denominado complejo Ses Mamelles. Fue explorada en 1974 por el Speleo Club de Mallorca, cuyos miembros hallaron cerca de la entrada gran cantidad de cerámica de dos tipos principalmente: vasos de cuerpo globular sin cuello y asas verticales junto al borde, y otros también globulares pero de cuello alto y marcado, en ocasiones con labio exvasado y también asas. Estas pueden ser macizas o perforadas (Fig. 7). La presencia de restos de fauna, mamíferos (capra, bos, ...) y moluscos diversos, hizo pensar a sus descubridores que se trataba de un lugar de hábitat muy provisional, debido a lo estrecho e incómodo de la cueva. La cronología que le asignaron es del final del pretalayótico (Trías-Roca, 1975).

Cova Xives se encuentra en Ibiza, concretamente en el Puig Guixa $(229 \mathrm{~m}$.), a menos de $2 \mathrm{~km}$. al noroeste del pueblo de Nta. Sra. de Jesús. Explorada también en los años setenta por el Speleo Club de Mallorca, esta pequeña cueva $(20$ por $10 \mathrm{~m}$.) proporcionó en prospección superficial gran cantidad de cerámicas, la mayoría a mano pero también algunas púnico-ebusitanas tardías (Trías, 1977). Se trata de formas globulares y troncocónicas, con asas de botón, pastas oscuras (sobre todo grises y negras) que permiten al descubridor sugerir una fecha en torno al 1500 a. J.C. para las más antiguas (troncocónicas) y de transición pretalayótico-talayótico para las otras, al igual que en la Cova des Riuets. Hay que destacar que sus descubridores insisten en general, a través de sus publicaciones, en la semejanza que se da con paralelos mallorquines y menorquines, pensando que las Pitiusas tienen en esa época una secuencia cultural semejante a la de las islas mayores.

Como vemos, estas tres cuevas sugieren todavía más interrogantes que soluciones y sólo el estudio en profundidad de sus materiales así como su excavación (en especial Cova Xives, la más accesible) permitirán fecharlas correctamente y darles un mayor peso en el marco de la prehistoria pitiusa.

\section{LOS MEGALITOS DE CAN SARGENT (IBIZA) (Lám. II, a)}

Estos dos importantes restos se encuentran en el Plá de S. Jorge, cerca del aeropuerto, y fueron explorados parcialmente en 1978; se excavó la mitad aproximadamente de Can Sargent I y se levantó la planimetría de los restos visibles de Can Sargent II. Una de las excavadoras, C. Topp, nos comentó recientemente (junio 1986) sus serias dudas sobre la exacta adscripción cronológica de Can Sargent II. A la espera de nuevas excavaciones, seguimos aquí lo expuesto en las publicaciones citadas (Topp et alii, 1979; Fernández-Topp, 1984).

Se trata de dos sepulcros de corredor separados entre sí por unos quince metros, construidos con grandes bloques de piedras de $1 \mathrm{~m}$. por 0,50 m., aproximadamente. De Can Sargent I se pudo despejar el corredor (de más de $2 \mathrm{~m}$.) y buena parte de la cámara (Fig. 8), mientras que de Can Sargent II sólo son visibles los ortostatos que parecen formar el corredor. Por lo que a hallazgos se refiere (Fig. 9), la cerámica recuerda de lejos la de $\mathrm{Ca} \mathrm{Na}$ Costa, pero su textura es mucho más dura y en general es más basta. Esto, unido al hecho de que algún fragmento con asa tiene claros paralelos en el Talayótico Inicial de Mallorca y Menorca, sugirió a los excavadores una cronología algo más tardía que la del sepulcro de Formentera. Esta suposición podría verse confirmada por el hallazgo en el sector suroeste de la cámara de un pequeño puñal triangular de bronce con dos remaches, de un tipo bien conocido en Levante y en Mallorca. Se trata de un elemento metálico típico de la cultura argárica (Lull, 1983: 155-178), pero que se encuentra además con frecuencia en Mallorca, tanto en yacimientos funerarios como de hábitat: Sa Canova, Sa Mata, Son Maiol, Naveta Alemany, etc... (Veny, 1968: figs. 156 y 170; Roselló Bordoy, 1974: 116-117). Si estos puñalitos deben considerarse o no de producción local es un problema que ha interesado a diversos autores. 

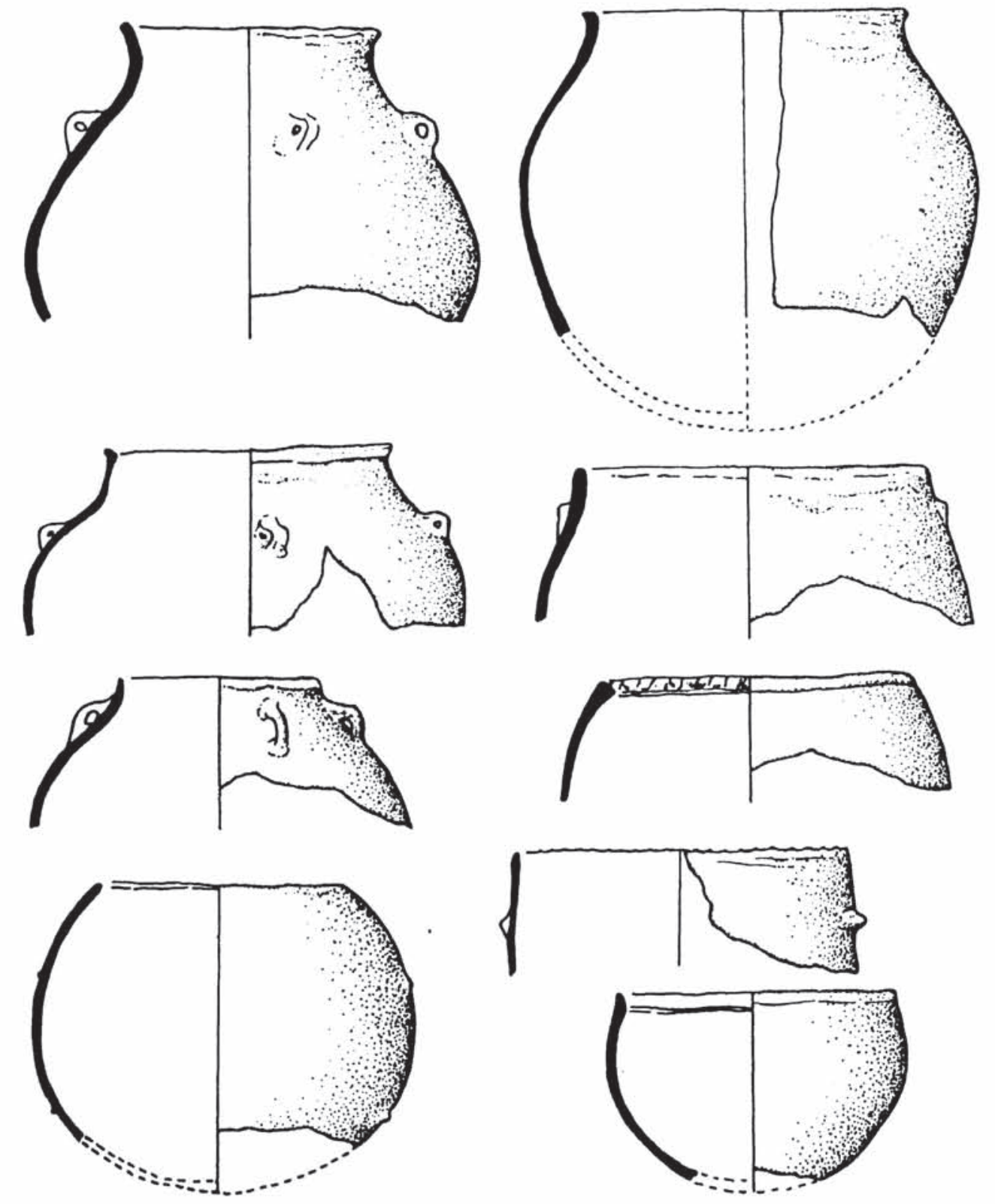

0

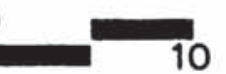

Fig. 7.- Cerámicas diversas de la Cova des Riuets, en Formentera (adaptado de Ramón, 1985 y Trías, 1975). 


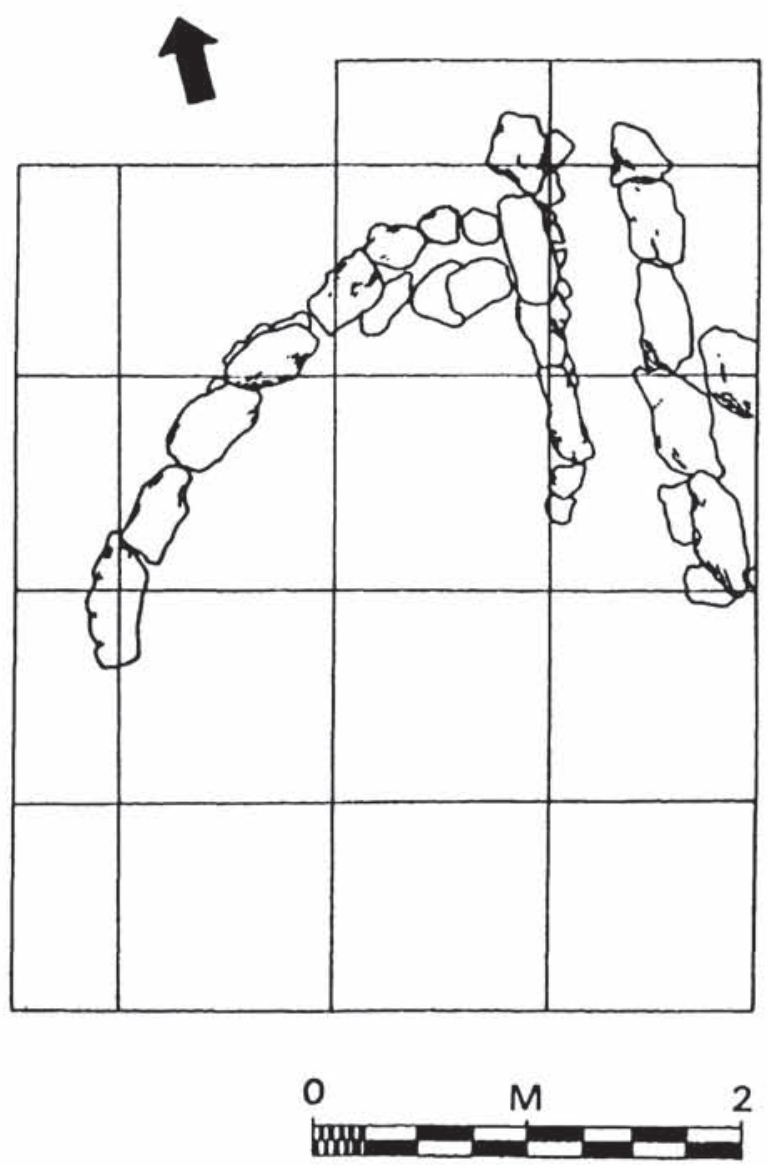

FIG. 8.- Planta del área excavada del sepulcro megalítico Can Sargent I, en Ibiza (según Topp et alii, 1979).

Para Veny su fabricación en Mallorca sería incluso anterior a la argárica, apoyando esta idea especialmente en las diferencias técnicas y también en la inexistencia de ejemplares en Ibiza, que debería haber sido lógicamente alcanzada por la difusión del tipo si este procediese del Sureste (Veny, 1968: 400). Por el contrario, Fernández-Miranda, que no cree en una procedencia argárica estricta de los puñalitos, disiente en cuanto a la mayor antigüedad de las piezas mallorquinas $\mathrm{y}$ opina que se trata de objetos que tienen, en efecto, sus prototipos en El Argar, de donde se difundirian por otras áreas, incluidas las Baleares. Las diferencias técnicas deben achacarse a un peor conocimiento de la metalúrgica por parte de los isleños (Fernández-Miranda, 1978: 152-153). Por eso, las piezas baleáricas, incluidas la ibicenca, son de bastante peor calidad que las peninsulares. En cualquier caso, de lo que no cabe duda es de que estos puñalitos, en Mallorca, se sitúan en el período pretalayótico, con una amplia cronología comprendida entre 1700 y 1300 a. J.C.

Desgraciadamente dos fechas de C14 obtenidas para Can Sargent no vienen a confirmar la datación que sugieren las cerámicas, el puñal y las mismas estructuras. Estas fechas son:

$$
\begin{array}{lll}
\text { BM }-1510 & 700 \text { B.C. } & (=550 \pm 100 \text { b.c. }) \\
\text { BM }-1511 & 800 \text { B.C. } & (=720 \pm 60 \text { b.c. })
\end{array}
$$

Ambas muestras proceden de restos humanos, los primeros hallados cerca del puñal (pero no asociados a él), y los segundos fuera de la cámara. Este problema, a nuestro entender importante 

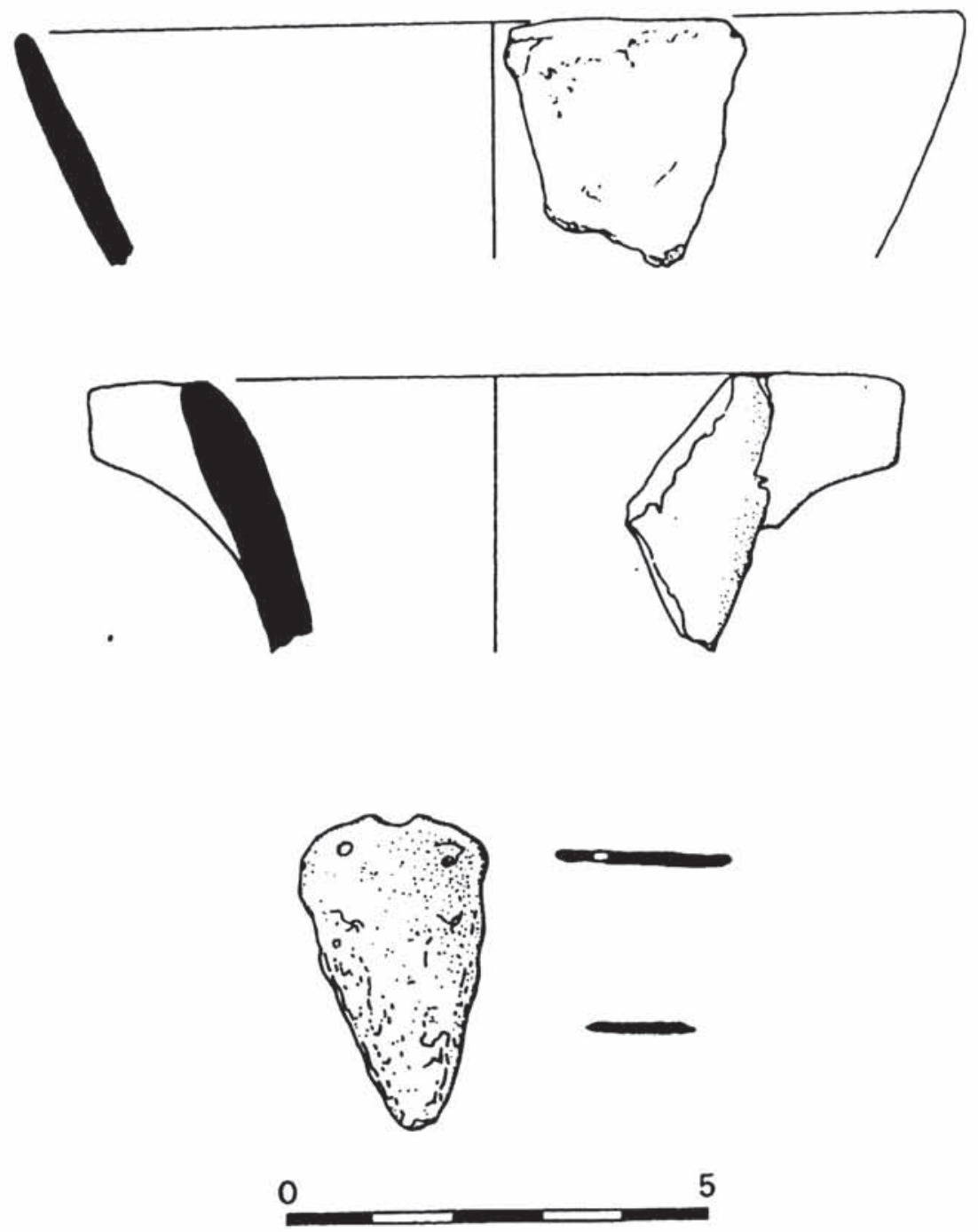

Fic. 9.- Cerámicas y puñalito de bronce de Can Sargent (según Topp et alii, 1979).

para valorar la presencia indígena en los siglos inmediatamente anteriores a la llegada de los fenicios, sólo puede solventarse si pensamos:

a) que las muestras estaban contaminadas y la fecha es equivocada; los restos humanos podrian corresponder, efectivamente, al sepulcro;

b) que las fechas de $\mathrm{C} 14$ son correctas, pero como difícilmente se podría rebajar la cronología del monumento y el ajuar del s. XIII a. J.C., hay que pensar que hubo una reutilización funeraria en el s. VIII a. J.C. Como no hay ningún resto material de esta fecha, aparte de los propios huesos humanos, resulta imposible fijar una adscripción cultural para estos enterramientos.

Hasta que no se complete la excavación del yacimiento resulta de todos modos aventurado intentar extraer más conclusiones. Pero queremos subrayar que si Can Sargent es una prueba segura del poblamiento de Ibiza en el segundo milenio a. J.C., su utilización durante la primera mitad del primer milenio plantea todavía demasiadas dudas. Las dos fechas de C14 nos parecen un argumento claramente insuficiente si no van acompañadas por elementos materiales. 


\section{OTROS YACIMIENTOS}

Presentamos en este apartado diversos yacimientos de importancia muy diferente, que para el tema aquí planteado, la prehistoria de las Pitiusas, no aportan aún demasiados datos bien por lo antiguo de su exploración, bien al contrario porque están por excavar, pero que indudablemente han de ser tenidos en cuenta.

\section{A) Recinto fortificado de Sa Cala (Formentera)}

Se encuentra en la parte más alta y oriental de la isla, La Mola, en su costa norte. Del posible recinto no queda más que un gran muro rectilíneo hecho de grandes ortostatos en doble alineación paralela dejando un espacio intermedio de aproximadamente 1,5 m. que se debió rellenar con piedra menuda y tierra (Fig. 10). El tramo conservado mide cerca de 38 metros y los ortostatos son de buen tamaño. Destacan los que flanquean dos puertas de acceso al recinto, que alcanzan $2 \mathrm{~m}$. de largo por $1,10 \mathrm{~m}$. de alto (conservado) y $0,55 \mathrm{~m}$. de grosor. Las puertas están separadas entre sí por unos $18 \mathrm{~m}$. (Ramón, 1985: 63-65). El material arqueológico es muy reducido, ya que la construcción se encuentra sobre la roca madre, sin prácticamente nivel alguno de tierra. Los pocos fragmentos cerámicos recogidos (Fig. 11), han sido puestos en relación con $\mathrm{Ca} \mathrm{Na}$ Costa, a excepción de dos de ellos con asas perforadas verticales (Topp et alii, 1979: 224-225). Esta pobreza de datos y el hecho de que el yacimiento no esté excavado impiden hacer mayores consideraciones. Se trata de un recinto defensivo, no cabe duda, a $15 \mathrm{~m}$. del borde de un acantilado de un centenar de metros de altura. Posee, pues, una magnífica posición y una excelente vista sobre Formentera, las costas sur y sureste de Ibiza y el estratégico estrecho de Els Freus, que separa ambas islas. Decir cuándo y contra quién se defendian los constructores del recinto es algo que nos resulta hoy por hoy casi imposible.

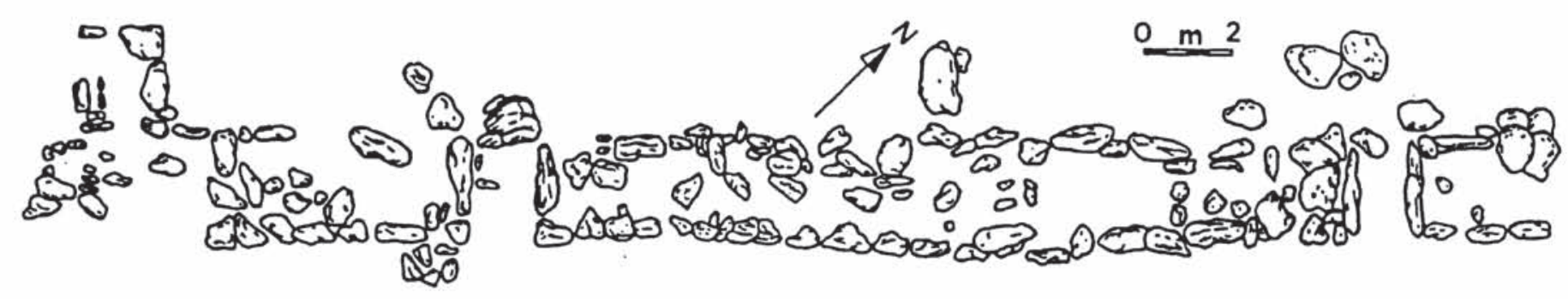

Fig. 10.- Planta del muro conservado de la fortificación de Sa Cala, en Formentera (según Ramón, 1985).
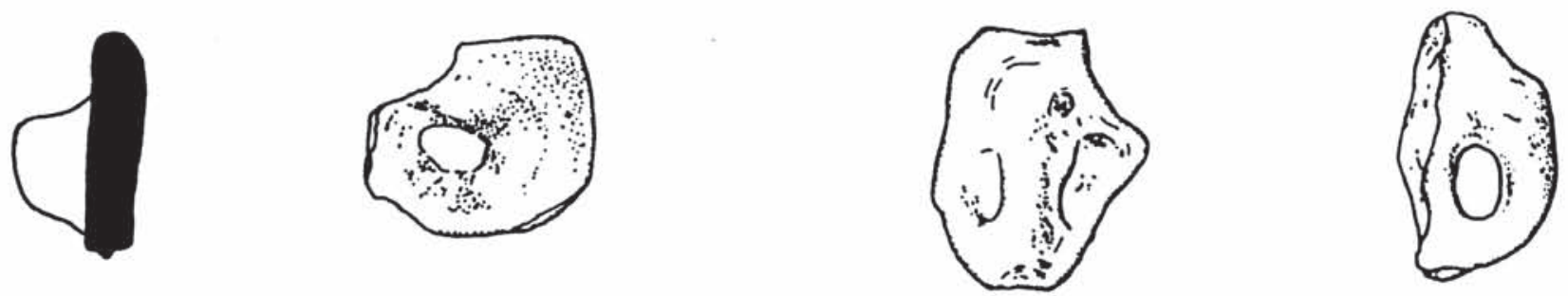

0

5

Fig. 11.- Fragmentos cerámicos de la fortificación de Sa Cala (según Topp et alii, 1979). 


\section{B) El Puig d'Es Jondal (Ibiza)}

Este yacimiento ha sido dado a conocer muy recientemente y son pocos los datos que se tienen, ya que no se ha excavado.

Correspondería a un hábitat en la punta Jondal, al sur de la isla, del que el elemento mejor conservado y de mayor interés es un muro defensivo de cerca de $300 \mathrm{~m}$. de perímetro conservado, que sigue la costa recortada a unos $30 \mathrm{~m}$. de altura. La técnica constructiva difiere bastante de lo que hemos visto hasta ahora. Consiste en un apilamiento de losas más o menos planas no trabajadas, de hasta $1 \mathrm{~m}$. de ancho y $0,40 \mathrm{~m}$. de grosor, formando hiladas horizontales que alcanzan en algunos tramos hasta $1,5 \mathrm{~m}$. El material recogido en superficie, al parecer escaso pero significativo, consiste en cerámica a mano que su descubridor atribuye al Bronce Antiguo, a una época no muy avanzada dentro del segundo milenio (Ramón, 1985: 65-66). La presencia esporádica de fragmentos de ánfora fenicia de los s. VII-VI a. J.C. debe relacionarse con el cercano asentamiento de Sa Caleta (2) y no indica la coexistencia de indígenas y colonizadores, ya que como se ha dicho, la cerámica a mano parece ser del segundo milenio. En cualquier caso, el yacimiento está pendiente de excavación para poder concretar tanto la cronología como su función exacta.

\section{C) La cueva de Es Cuieram (Ibiza)}

Se trata, sin duda, de uno de los yacimientos más conocidos de la isla, y desde su descubrimiento en 1907 la riqueza e importancia de los hallazgos sucesivos allí realizados ha suscitado el interés de numerosos investigadores. Los centenares de terracotas que representan la diosa Tanit han permitido valorar la cueva como un santuario dedicado a dicha divinidad, con un período de utilización comprendido entre los inicios del s. IV y mediados del s. II a. J.C., con una prolongación de uso como posible hábitat hasta el cambio de era. La abundante bibliografía sobre la cueva en época púnica, a la que remitimos, nos exime de extendernos sobre el proceso de descubrimiento e investigación (Aubet, 1982: 9-12; Ramón, 1985b: 228-230).

El interés de la cueva para la fase que estamos estudiando aquí reside en la existencia de cerámicas a mano que han sido recogidas en varias ocasiones y que han planteado la posible utilización de Es Cuieram en la Edad del Bronce. En la primera obra de conjunto sobre el yacimiento, C. Román, uno de los excavadores de la primera campaña de 1907, no menciona nigún tipo de cerámica prehistórica (Román, 1913). Sin embargo, muy pocos años después, A. Vives y Escudero - que también participó en la primera campaña- en su obra clásica sobre Ibiza dio a conocer tres fragmentos de cerámica que él consideró neolítica, encontrados durante sus propias excavaciones en 1909. Son de "barro basto y mal cocido", dos con asas de botón (uno perforado) y otra de borde decorado "con una orla de adornos de forma ondulada" (posiblemente una decoración de cordón aplicado). Desconocemos el paradero actual de estas piezas. Pero el dato más interesante aportado por Vives tal vez sea el de su procedencia: al fondo de la cueva, en un nivel más profundo que el de las terracotas púnicas, bajo una ligera capa de sedimento calcáreo (Vives, 1917: 2-4). A lo largo de las décadas siguientes estos fragmentos cerámicos fueron uno de los puntos de apoyo para diversos autores que aseguraban una ocupación pre-púnica de la isla (Sorá Boned, 1944; Macabich, 1966: 4-5). Cuando aparece el primer estudio moderno sobre la cueva, su autora hace referencia a las cerámicas de Vives, pero cree que es difícil adscribirlas culturalmente, tanto más cuando "no se conocen aún restos arqueológicos anteriores a la llegada de los cartagineses" (Aubet, 1968: 38-39).

Cuando por fin se realizan nuevas excavaciones en los años sesenta, aparecen tres fragmentos más de cerámica a mano. Pertenecen a cuencos semiesféricos, son de pasta fina de color parduzco, bien cocida. Dos de ellos tienen asas de botón perforado, el otro una pequeña asa vertical de

(2) Las excavaciones del yacimiento fenicio de Sa Caleta, al sur de la isla de Ibiza, están proporcionando estructuras y materiales que tal vez haya que fechar en la 1." mitad del siglo VII a. J.C. Agradecemos estos datos al director de los trabajos (aún en curso) J. Ramón. 
sección circular. Sus publicadores creen que tienen una tradición en el Bronce del Sureste y, por lo tanto, que podrían ser de cronologia antigua. Pero no se definen claramente, pues añaden que cerámicas semejantes se siguen fabricando durante siglos, como sucede en la cultura talayótica (Almagro-Fortuny, 1971: 24-25).

Finalmente, a raíz de una campaña de limpieza realizada en 1981 para facilitar el levantamiento topográfico de la cueva, aparecieron algunos fragmentos más hallados en superficie o entre los escombros de las viejas excavaciones. Se trata de un cuenco con botón vertical perforado, otro borde de cuenco hemisférico, una base plana y algunos fragmentos más. La pasta es de calidad, bien cocida, con diversas tonalidades y con las superficies externas espatuladas, de color gris oscuro (Ramón, 1985b: 240-241). Un detalle significativo es que algunos fragmentos presentan adherencias calcáreas que parecen confirmar lo dicho por Vives en cuanto a la estratigrafía. Este hecho y la tipologia reconstruible hacen pensar a J. Ramón que se trata realmente de cerámicas del Bronce, y que Es Cuieram sería entonces un lugar de hábitat, muchos siglos antes de convertirse en un santuario rupestre púnico.

Como vemos, los datos de que disponemos para opinar son muy escasos, una docena escasa de fragmentos recogidos a lo largo de casi ochenta años, que deberían ser reestudiados detenidamente. Si nos inclinamos a aceptar, sin embargo, su antigüedad, en especial por la referencia estratigráfica de Vives, nos parece totalmente imposible asignarles una cronología exacta: cualquier fecha entre 1500 a. J.C. y el siglo VIII podría ser correcta.

\section{D) El abrigo De Ses Fontanelles (Ibiza)}

Este pequeño abrigo rocoso se encuentra al norte de San Antonio, muy cerca del Puig Nonó. Orientado hacia el sur, en sus paredes se encuentran algunas pinturas que fueron estudiadas por H. Breuil durante un viaje a Ibiza en 1917 y publicadas poco después (Breuil, 1920). Están trazadas en negro, ocupando un espaciǫ de tan sólo $0,70 \mathrm{~m}$. de largo, y representan un "entrelacement de traits courbes et rectilignes de difícil interpretación. Para Breuil, que hizo un croquis lo más exacto posible pero que no pudo sacar un calco, parecen representar una nave de popa cuadrada y proa apuntada. Con mucha prevención se aventuró a fecharlas en la Edad del Bronce, como límite postquem debido a la existencia de algunas hachas de bronce en Formentera. Cuarenta años después, en la correspondencia que mantuvo con el erudito ibicenco, I. Macabich, Breuil sólo expresó que no le parecieron recientes, y aconsejó a Macabich que subrayara las dudas sobre la edad de las pinturas (Macabich, 1966: 9-10). De las cartas intercambiadas entre ambos estudiosos se desprende que pensaban que no existían representaciones rupestres cartaginesas, lo que hacía probable una fecha antigua para las pinturas. Hoy conocemos, sin embargo, diversas representaciones rupestres fechables en época púnica, destacando las de Gotta Regina en Sicilia, donde precisamente son frecuentes las representaciones de naves de diferentes tipos (Bisi et alii, 1969; Coacci Polselli et alii, 1979), y en Jimena de la Frontera (Cádiz), donde se ha estudiado un importante conjunto de pinturas en el Abrigo de Loja Alta que incluyen un puerto o fondeadero y también diversas naves, en un ambiente claramente influenciado por la cercana metrópolis fenicia de Gadir (Barroso, 1980: 34-42).

Creemos que la cercanía de Ses Fontanelles al mar (desde donde es muy fácil acceder) y la existencia de pequeños manantiales de agua en el mismo abrigo - hoy desaparecidos- y en otras pequeñas cuevas cercanas, que justifican sobradamente el topónimo, inducen a pensar que una cronología más baja que la propuesta hasta ahora es cuando menos plausible y que el lugar pudo ser frecuentado por marinos y pescadores en época púnica. En cualquier caso habrá que esperar que se realice un estudio actualizado del conjunto, si es que sobrevive al vandalismo y a las pintadas modernas que amenazan el abrigo. 
CUADRo I

CRONOLOGLA DE LOS PRINCIPALES YACIMIENTOS PREHISTORICOS DE LAS PITIUSAS

\begin{tabular}{|c|c|c|c|}
\hline YACIMIENTO & SITUACION & $\underset{\text { C. } 14}{\text { CRONOLOGIX }}$ & $\begin{array}{l}\text { CRONOLOGIA } \\
\text { POSIBLE }\end{array}$ \\
\hline $\begin{array}{l}\text { Ca Na Costa } \\
\text { Can Sargent } \\
\text { Cap de Berberia (Poblado y circulos) } \\
\text { Cova de Riuets } \\
\text { Cova Xives } \\
\text { Cova d'Es Fum } \\
\text { Sa Cala } \\
\text { Puig Jondal } \\
\text { Es Cuieram (1." fase) } \\
\text { Ses Fontanelles } \\
\text { Depósito La Sabina } \\
\text { Depósito Can M. Gallet }\end{array}$ & $\begin{array}{l}\text { Formentera } \\
\text { Ibiza } \\
\text { Formentera } \\
\text { Formentera } \\
\text { Ibiza } \\
\text { Formentera } \\
\text { Formentera } \\
\text { Ibiza } \\
\text { Ibiza } \\
\text { Ibiza } \\
\text { Formentera } \\
\text { Formentera }\end{array}$ & $\begin{array}{l}1600 \text { B.C. } \\
800-700 \text { B.C. } \\
= \\
= \\
= \\
= \\
= \\
= \\
=\end{array}$ & $\begin{array}{c}1600 \text { a. J.C. } \\
1500-1300 \text { a. J.C. } \\
\text { circa } 1500 \text { a. J.C. } \\
\text { I." mitad II milenio } \\
\text { I." mitad II milenio } \\
\text { I. mitad II milenio } \\
1 . \text { mitad II milenio } \\
\text { 1. mitad II milenio } \\
1500-800 \text { a. J.C.? } \\
\text { ? } \\
800-600 \text { a. J.C. } \\
800-600 \text { a. J.C. }\end{array}$ \\
\hline
\end{tabular}

\section{E) La Cueva de Portusalé (Formentera)}

No podemos dejar de citar, para terminar este epigrafe dedicado a los yacimientos que pueden aportar datos sobre la prehistoria pitiusa, una cueva hallada a principios de siglo en la zona de Portusalé (Portossaler en los documentos antiguos), al oeste de Formentera. Pérez Cabrero recogió de unos campesinos la noticia de que se había encontrado una cueva en cuyo interior había siete u ocho esqueletos humanos enteros, en posición sentada, y junto a ellos varias cerámicas, algunas rotas (Pérez Cabrero, 1909: 109; 1911: 34). Tanto por tratarse de una cueva como por lo extraño de la disposición de los muertos, se ha querido ver en ello un enterramiento prehistórico, sin que se disponga de más datos que los mencionados, ya que la cueva fue destruida por los mismos campesinos que la descubrieron. Sin embargo, su emplazamiento exacto es conocido y no puede descartarse que una futura excavación pueda aportar datos de interés, a pesar del mal estado de conservación.

\section{LA METALURGIA DE BRONCE}

Un buen número de objetos de bronce. hallados a lo largo de varias décadas de manera casual han supuesto, durante muchos años, el único elemento con que se contaba para plantear la existencia de una prehistoria pitiusa. Un puñal, un lingote y sobre todo hachas de diversos tipos eran claros indicios, antes de la excavación del megalito de $\mathrm{Ca} \mathrm{Na}$ Costa, de que si no tuvieron población estable, ambas islas habrían sido al menos frecuentadas antes del s. VII a. J.C. Sin embargo, hasta hace escasas fechas, la mayoría de estas piezas habían sido correctamente publicadas, pero no habían sido estudiadas en profundidad (Fernández, 1973; 1974). Un detallado trabajo recientemente publicado nos permite perfilar mejor cronologías y paralelos, al menos para los ejemplares más tardíos (Delibes-Fernández-Miranda, 1984).

El total de objetos conocidos para la investigación es (véase cuadro II):

- 1 puñal subtriangular hallado en Ibiza, procedencia desconocida. 
CUADRO II

HALLAZGOS DE BRONCES PREHISTORICOS EN LAS PITIUSAS

\begin{tabular}{|c|c|c|c|c|c|c|c|c|}
\hline Lugar del hallaxgo & Puñales & $\begin{array}{l}\text { Hachas } \\
\text { planas }\end{array}$ & $\begin{array}{c}\text { Hachas } \\
\text { de } \\
\text { cubo }\end{array}$ & $\begin{array}{c}\text { Hachas } \\
\text { de } \\
\text { talón }\end{array}$ & $\begin{array}{l}\text { Hachas de } \\
\text { apéndices } \\
\text { laterales }\end{array}$ & Lingotes & Cronologia & $\begin{array}{l}\text { Paradero } \\
\text { actual }\end{array}$ \\
\hline $\begin{array}{l}\text { Isla de Ibiza, } 1907 \\
\text { Cala Xarraca, c. } 1927 \\
\text { Ses Salines, 1910 } \\
\text { Sa Bassa Rotja, } 1969 \\
\text { La Sabina, } 1910 \\
\text { Can M. Gallet } \\
\text { Can Sargent, } 1977\end{array}$ & 1 & $\begin{array}{l}2 \\
2 \\
1\end{array}$ & 1 & 4 & $\begin{array}{l}1 \\
4\end{array}$ & 1 & $\begin{array}{l}\text { c. } 1500 \text { a. J.C. } \\
\text { VIII-VII a. J.C. } \\
\text { IX-VIII a. J.C. } \\
\text { VIII-VI a. J.C. } \\
\text { VIII-VII a.J.C. } \\
\begin{array}{c}1700-1300 \text { a. } \\
\text { J.C. }\end{array}\end{array}$ & $\begin{array}{c}\text { M.A.I. } \\
\text { Desconocido } \\
\text { Desconocido } \\
\text { Col. J. Mari } \\
\text { Tur (Ibiza) } \\
\text { M.A.I. } \\
\text { M.A.I. } \\
\text { M.A.I. }\end{array}$ \\
\hline
\end{tabular}

- 5 hachas planas procedentes de Cala Xarraca, Ses Salines y Sa Bassa Rotja, en Ibiza.

- 2 hachas de cubo de Ses Salines (Ibiza) y La Sabina (Formentera).

- 4 hachas de talón y anillas de Can Mariano Gallet (Formentera) (Fig. 12).

- 5 hachas de apéndices laterales de Can Mariano Gallet (Fig. 13) y La Sabina (Formentera).

- 1 lingote plano convexo de La Sabina (Formentera) (Lám. II, b)

No incluimos el puñalito de Can Sargent, el único procedente de una excavación científica y que hemos estudiado en el lugar correspondiente (véase supra, apartado 4).

Como hemos señalado, las piezas más antiguas no han sido valoradas suficientemente. De las cinco hachas planas de las que se tiene noticia, sólo una se conserva para la investigación, la de Sa Bassa Rotja; las demás han desaparecido, y sólo se conoce un deficiente dibujo de uno de los ejemplares de Xarraca (Sorá Boned, 1944: 18; Mari Tur, 1973; Fernández, 1974: láms. II-III).

Los ejemplares conocidos son de un tipo muy extendido cuyo origen está probablemente en el SE peninsular, a finales del tercer milenio. Adaptación al metal de los antiguos modelos en piedra pulida, las hachas planas gozarán de una gran aceptación y por ello las encontramos a lo largo de toda la Edad del Bronce. Existen, sin embargo, elementos que permiten matizar su cronología.

El ejemplar hallado cerca de Cala Xarraca era estrecho, casi trapezoidal, con los bordes lisos y levemente curvados en ambos extremos; se supone que el otro ejemplar perdido del que no se conserva dibujo era semejante. Esta forma alargada y con el arco del filo poco marcado podría ser antigua, pues se encuentra en época de Los Millares, c. 2000 a. J.C. Sin embargo, prolonga su existencia a lo largo del Bronce Antiguo, conociéndose ejemplares parecidos al nuestro en Andalucía (Blance, 1971, lám. 13; Harrison-Craddock, 1981: 117-119) y Cataluña (Martí, 1970: 108-115). Piezas de este tipo antiguo no se conocen en otros lugares de Baleares, y son escasas en las áreas geográficas más cercanas a las islas: País Valenciano, etc... Podríamos fechar con reservas el ejemplar ebusitano en torno a mediados del segundo milenio.

El hacha de Sa Bassa Rotja es más fácil de encuadrar tipológica y cronológicamente. De casi 17 $\mathrm{cm}$., tiene forma trapezoidal con un filo muy marcado en arco de círculo, con salientes laterales y el talón plano. Estos rasgos definen un tipo de hacha que conoce una gran expasión por gran parte de la Península Ibérica, en especial en Andalucía y Portugal (Blance, 1971: láms. 23-24; Schubart, 1975: láms. 47-50), pero también en otras zonas más al norte (Harrison-Craddock, 1981: 118-125), con algunos ejemplares en el País Valenciano y en Cataluña (Lerma, 1981: 137; Martí, 1970: 108-117). También aparecen en Mallorca, especialmente en una serie de depósitos de bronces bien conocidos. Merecen destacarse los de Es Mitjà Gran (Sea Salines) y Cas Corraler (Felanitx), con cinco y dos hachas, respectivamente. En ambos casos se les asignó una cronología bastante baja: s. VII-V a. J.C. para el primero (Almagro, 1962: E.8.2) y VIII-V a. J.C. para el segundo (Almagro, 1967: E.19). Sin 

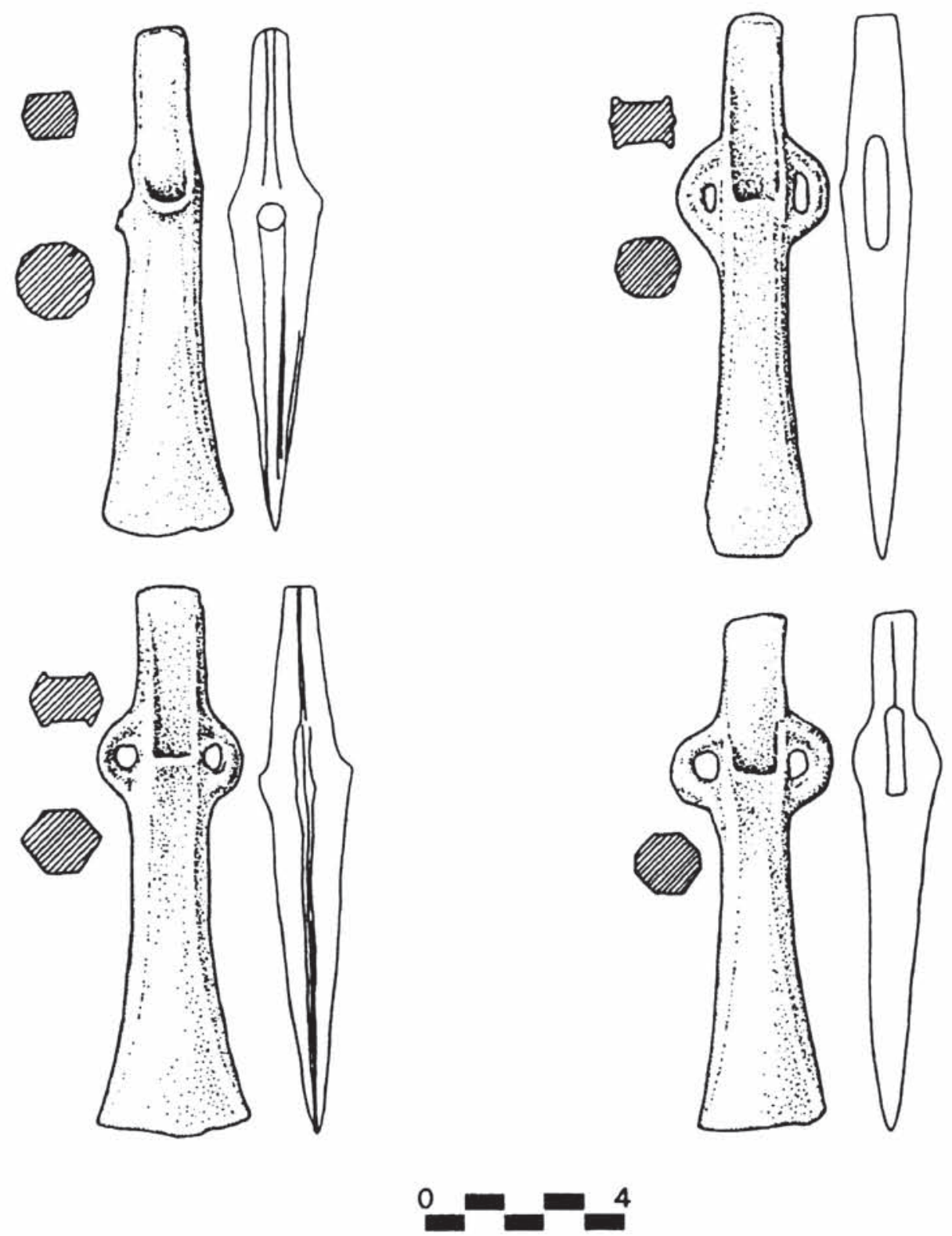

FIG. 12.- Hachas de talón del depósito de Can Mariano Gallet, en Formentera (según Delibes-Fernández-Miranda, 1984).

embargo, en fechas más recientes se han reconsiderado las dataciones. Así Roselló Bordoy sitúa Cas Corraler en torno al 1000 a. J.C. y Es Mitjà Gran hacia el 900 a. J.C., dentro de su fase del Talayótico I, aunque con muchas dudas (Roselló Bordoy, 1974: 120, fig. 2). Por su parte, Fernández-Miranda tampoco cree que esos conjuntos puedan ser de fechas tardías. Incluso subraya que el tipo plano corresponde en general, en otras áreas, al Bronce II mediterráneo, con fechas dentro del segundo milenio. Pero su asociación en depósitos con espadas de pomo y escoplos le sugiere una datación intermedia entre la de los paralelos externos y la tardía propuesta por Almagro: en torno a los s. IXVIII a. J.C., dentro de su Talayótico I o Antiguo (Fernández-Miranda, 1978: 93-99, 210). 
El lote más numeroso de objetos de bronce lo constituyen las hachas de cubo, de talón y de apéndices laterales, que han merecido recientemente un exhaustivo estudio en el ámbito de todas las Baleares, que resumimos muy brevemente (Delibes-Fernández-Miranda, 1984).

De las quince hachas de cubo conocidas en Baleares, sólo dos proceden de las Pitiusas: una de Ibiza y otra de Formentera. Los autores más arriba citados las incluyen en uno de sus tipos que denominan «balean (ya que está representado en las cuatro islas mayores), al que consideran local, pero producto de la adaptación de prototipos foráneos. La búsqueda de estos prototipos es ciertamente difícil, pues si el tipo «balear tiene ciertos paralelos en modelos británicos, no cabe ponerlo en relación con el grupo más importante de hachas de cubo peninsular, el llamado galaicoportugués (Hardaker, 1976: 162-163) debido a las claras diferencias morfológicas existentes. Habría, por el contrario, algunas semejanzas con la zona del Noreste peninsular pero sobre todo con el Midi francés, donde el tipo llamado launaciense parece ser un prototipo claro (Chardenoux-Courtois, 1979: 122-127).
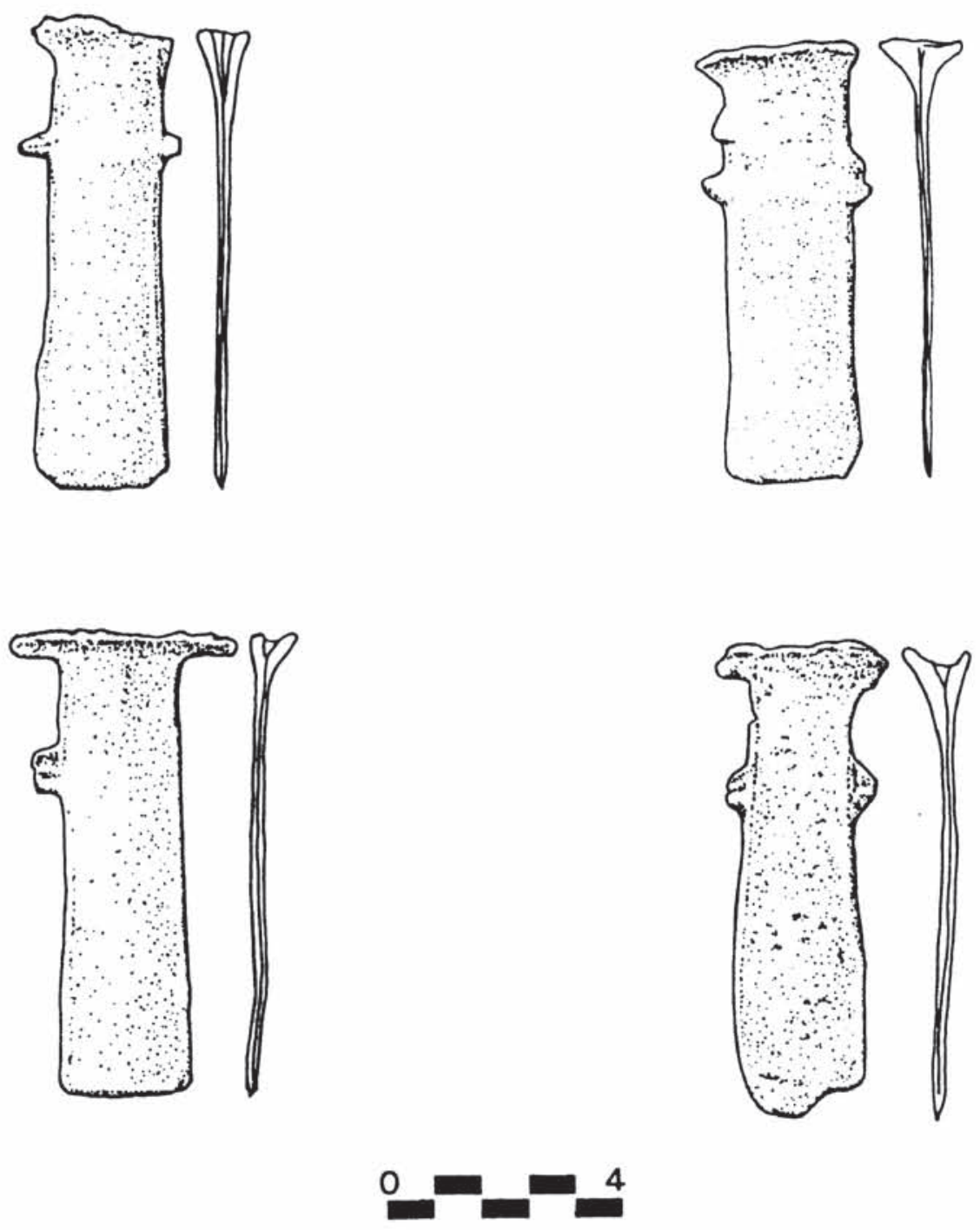

FIG. 13. - Hachas de apéndices de Can Mariano Gallet, en Formentera (según Delibes-Fernández Miranda, 1984). 
CUADRO III

ANALISIS OUIMICO DE LAS DIFERENTES HACHAS HALLADAS EN IBIZA Y FORMENTERA

\begin{tabular}{|c|c|c|c|c|c|c|c|c|c|c|c|c|}
\hline Procedencia & $\begin{array}{l}\text { Museo } \\
\text { N.: }\end{array}$ & Sn & As & sb & $\mathbf{P b}$ & co & NI & $\mathbf{F e}$ & $A_{8}$ & $\mathbf{A u}$ & $\mathbf{z} \mathbf{n}$ & BI \\
\hline $\begin{array}{l}\text { 1 Can Mariano, } \\
\text { Gallet, } \\
\text { Formentera }\end{array}$ & $\underset{1}{\text { Ibiza }}$ & $\begin{array}{l}\bar{z} \\
-\end{array}$ & $\begin{array}{l}0,06 \\
-\end{array}$ & $\begin{array}{l}0,04 \\
-\end{array}$ & $\begin{array}{l}\overline{0.19} \\
0.17\end{array}$ & $\bar{z}$ & $\begin{array}{l}0,08 \\
0,12 \\
0,10\end{array}$ & $\begin{array}{l}0,01 \\
=\end{array}$ & $\begin{array}{l}0,02 \\
0,02 \\
0,08\end{array}$ & $\begin{array}{l}0,03 \\
-\end{array}$ & $\bar{z}$ & $\bar{z}$ \\
\hline $\begin{array}{l}\text { 2Can Mariano, } \\
\text { Gallet }\end{array}$ & $\underset{2}{\text { Ibiza }}$ & $\overline{0.03}$ & $\begin{array}{l}0,10 \\
0,16 \\
-\end{array}$ & $\bar{z}$ & $\begin{array}{l}1,00 \\
0,47 \\
0,51\end{array}$ & $\bar{z}$ & $\overline{0,03}$ & $\overline{0,01}$ & $\begin{array}{l}0,07 \\
0,04 \\
-\end{array}$ & $\overline{0.09}$ & $\bar{z}$ & $\overline{\overline{-}}$ \\
\hline $\begin{array}{l}3 \text { Can Mariano, } \\
\text { Gallet }\end{array}$ & $\underset{3}{\text { Ibiza }}$ & $\overline{\bar{z}}$ & $\frac{0,04}{0,15}$ & $\overline{\overline{-}}$ & $\begin{array}{l}0,63 \\
0,28 \\
0,41\end{array}$ & $\bar{z}$ & $\begin{array}{l}0,08 \\
0,09 \\
0,05\end{array}$ & $\begin{array}{l}0,01 \\
0,01 \\
0,01\end{array}$ & $\begin{array}{l}0,04 \\
0,02 \\
0,03\end{array}$ & $\begin{array}{l}0,05 \\
=\end{array}$ & $\overline{0,02}$ & $\begin{array}{l}0,06 \\
=\end{array}$ \\
\hline $\begin{array}{l}\text { 4Can Mariano, } \\
\text { Gallet }\end{array}$ & $\underset{4}{\text { Ibiza }}$ & $\begin{array}{l}5,15 \\
2,33 \\
2,62\end{array}$ & $\begin{array}{l}\overline{0.06} \\
0,04\end{array}$ & $\underline{0,02}$ & $\begin{array}{l}0,26 \\
0,19 \\
0,33\end{array}$ & $\overline{0,01}$ & $\begin{array}{l}0,06 \\
0,06 \\
0,02\end{array}$ & $\begin{array}{l}0,01 \\
-\end{array}$ & $\begin{array}{l}0,08 \\
0,05 \\
0,03\end{array}$ & $\bar{z}$ & $\bar{z}$ & $\frac{0,02}{0,02}$ \\
\hline $\begin{array}{l}5 \text { Can Mariano, } \\
\text { Gallet }\end{array}$ & $\underset{5}{\text { Ibiza }}$ & $\begin{array}{r}13,10 \\
8,28 \\
3,58\end{array}$ & $\begin{array}{l}0,38 \\
0,28 \\
0,10\end{array}$ & $\begin{array}{l}0,11 \\
0,06 \\
0,02\end{array}$ & $\begin{array}{l}0,72 \\
0,84 \\
0,46\end{array}$ & $\frac{0,01}{0,01}$ & $\begin{array}{l}0,06 \\
0,03 \\
0,07\end{array}$ & $\begin{array}{l}0,05 \\
0,10 \\
0,10\end{array}$ & $\begin{array}{c}0,08 \\
0,02 \\
-\end{array}$ & $\overline{0,06}$ & $\begin{array}{l}0,07 \\
0,16 \\
0,21\end{array}$ & $\bar{z}$ \\
\hline $\begin{array}{l}\text { 6Can Mariano, } \\
\text { Gallet }\end{array}$ & $\begin{array}{c}\text { Ibiza } \\
6\end{array}$ & $\overline{0,03}$ & $\begin{array}{l}0,05 \\
=\end{array}$ & $\begin{array}{l}0,02 \\
0,02 \\
-\end{array}$ & $\overline{0,10}$ & $\begin{array}{l}0,02 \\
-\end{array}$ & $\begin{array}{l}0,17 \\
0,19 \\
0,18\end{array}$ & $\bar{z}$ & $\begin{array}{l}0,07 \\
0,07 \\
0,07\end{array}$ & $\begin{array}{l}0,04 \\
0,07\end{array}$ & $\begin{array}{c}0,05 \\
=\end{array}$ & $\begin{array}{l}\bar{z} \\
\overline{-}\end{array}$ \\
\hline $\begin{array}{l}7 \text { Can Mariano, } \\
\text { Gallet }\end{array}$ & $\begin{array}{c}\text { Ibiza } \\
7\end{array}$ & $\bar{z}$ & $\overline{0,06}$ & $\bar{z}$ & $\overline{\overline{0}} \overline{08}$ & $\bar{z}$ & $\begin{array}{l}0,10 \\
0,08 \\
0,07\end{array}$ & $\begin{array}{l}0,01 \\
=\end{array}$ & $\begin{array}{l}0,05 \\
0.11 \\
0,10\end{array}$ & $\begin{array}{c}0,04 \\
=\end{array}$ & $\bar{z}$ & $\bar{z}$ \\
\hline $\begin{array}{l}8 \text { Can Mariano, } \\
\text { Gallet }\end{array}$ & $\underset{8}{\text { Ibiza }}$ & $\begin{array}{l}0,04 \\
0,05 \\
0,05\end{array}$ & $\overline{\overline{0,04}}$ & $\bar{z}$ & $\begin{array}{l}\overline{0,07} \\
0,04\end{array}$ & $\begin{array}{c}0,01 \\
0,01 \\
-\end{array}$ & $\begin{array}{l}0,06 \\
0,04 \\
0,06\end{array}$ & $\bar{z}$ & $\begin{array}{l}\overline{0,06} \\
0,06\end{array}$ & $\bar{z}$ & $\begin{array}{l}0,02 \\
0,03\end{array}$ & $\bar{z}$ \\
\hline $\begin{array}{l}9 \text { La Sabina, } \\
\text { Formentera }\end{array}$ & $\begin{array}{l}\text { MAI } \\
1492\end{array}$ & $\begin{array}{r}6,94 \\
5,77 \\
11,63\end{array}$ & $\begin{array}{l}0,23 \\
0,08 \\
0,12\end{array}$ & $\begin{array}{c}0,02 \\
-\end{array}$ & $\bar{z}$ & $\begin{array}{l}\overline{0,02} \\
0,02\end{array}$ & $\begin{array}{l}0,04 \\
0,04 \\
0,03\end{array}$ & $\overline{0,02}$ & $\overline{0,05}$ & $\bar{z}$ & $\bar{z}$ & $\overline{\overline{0,04}}$ \\
\hline $\begin{array}{c}10 \text { La Sabina } \\
\text { (lingote) }\end{array}$ & $\begin{array}{l}\text { MAI } \\
1493\end{array}$ & $\underline{0,02}$ & $\begin{array}{l}0,06 \\
0,09 \\
0,13\end{array}$ & $\begin{array}{l}0,07 \\
0,04 \\
0,06\end{array}$ & $\bar{z}$ & $\begin{array}{c}0,02 \\
- \\
-\end{array}$ & $\begin{array}{l}0,02 \\
0,05 \\
0,02\end{array}$ & $\frac{\overline{0.02}}{-}$ & $\begin{array}{l}0,09 \\
0,03 \\
0,09\end{array}$ & $\begin{array}{c}0,05 \\
- \\
-\end{array}$ & $\begin{array}{l}\bar{z} \\
-\end{array}$ & $\bar{z}$ \\
\hline 11 La Sabina & $\begin{array}{l}\text { MAI } \\
1494\end{array}$ & $\begin{array}{l}8,43 \\
8,67 \\
8,83\end{array}$ & $\overline{\overline{0.10}}$ & $\begin{array}{l}0,05 \\
0,05 \\
0,05\end{array}$ & $\frac{0,06}{=}$ & $\begin{array}{l}0,02 \\
0,01 \\
-\end{array}$ & $\begin{array}{l}0,22 \\
0,20 \\
0,28\end{array}$ & $\begin{array}{l}0,01 \\
0,01 \\
0,01\end{array}$ & $\begin{array}{l}0,06 \\
0,10 \\
0,05\end{array}$ & $\bar{z}$ & $\overline{0,02}$ & $=$ \\
\hline
\end{tabular}

Los otros tipos de hachas revisten un especial interés por cuanto sólo están representados en las Pitiusas, no conociéndose en la actualidad ni en Mallorca ni en Menorca. De las cinco hachas de apéndices laterales la de La Sabina, maciza y con dos apéndices, corresponde más al tipo clásico originario de Oriente que conoce una gran expansión hasta llegar a la Península Ibérica, donde es relativamente abundante. El hecho de que se trate de un unicum (veremos que las otras cuatro son muy diferentes) obliga a buscar su procedencia fuera de las islas, y al no existir en el norte de Africa ni en el Midi, parece que su origen debe ser sardo o peninsular. En efecto, el modelo es frecuente en Cerdeña, en el famoso depósito de Sa Idda y también en el de Flumenulongu, en fechas tardias del Bronce Final, destacando el hecho de que el ejemplar de La Sabina apareció junto con un lingote circular plano-convexo del tipo frecuente en los depósitos sardos (3). La posible procedencia peninsular la basan Delibes y Fernández-Miranda en un claro paralelo procedente del Camp de Tarragona (Martí, 1970: 134, fig. 14,4). Sin embargo, el mismo autor que publicó esta pieza subraya dos hechos importantes: que dicha pieza procede del comercio de antigüedades y que el

(3) Al parecer había varios lingotes más en el depósito de La Sabina (Fernández, 1974: 68), que han desaparecido; puede verse, sin embargo, un ejemplar en Vives, 1917: 4, fig. 7. 
tipo es "desusado" en la región. Personalmente opinamos que esto hace al paralelo poco digno de ser tomado en consideración.

Las otras cuatro hachas de apéndices resultan problemáticas, por cuanto son extremadamente endebles, al tener sólo algunos milímetros de espesor, conservar el cono de fundición en el extremo distal y tener diferente número de apéndices, resultado de una fundición poco cuidada con moldes bivalvos en los cuales las improntas de esos apéndices no coincidian. Estos "simulacros de hachas", como los denominó Siret, sólo se encuentran en el depósito de Elche (Almagro, 1967: E.13/2) y en el poblado de la Peña Negra de Crevillente, también en Alicante. Aqui el excavador rechazó la clasificación de hachas y creyó que eran un "positivo de bebedero de molde». Su aparición exclusivamente en Elche, Crevillente y Formentera le indujo a relacionar estas piezas con una labor de recogida de chatarra por parte de comerciantes semitas.

Más recientemente ha propuesto que se consideren estas piezas (ya numerosas en Peña Negra) como auténticos lingotes relacionables con el comercio semita, dado que de los análisis se desprende su gran pureza: $99 \%$ de cobre o de plomo, según los ejemplares, que hacen de ellas un excelente elemento de intercambio económico (González Prats, 1986). Los análisis realizados sobre las piezas pitiusas parece que apoyan esta hipótesis, ya que también tienen un alto grado de pureza (veáse Cuadro III).

Incluidas en la fase II de Peña Negra, fecha estos ejemplares en el 600/550 a. J.C. (González Prats, 1982: 373, fig. 28), datación que Delibes y Fernández-Miranda consideran tal vez correcta para dicho yacimiento, pero demasiado baja para los ejemplares de Can Mariano Gallet, ya que aquí se encuentran asociados con hachas de talón.

Estas hachas con talón y anillas son características del Bronce Final de la Península Ibérica y tienen diversas variantes. El máximo número de hallazgos se da en el Noroeste, siento esporádicos al sur del Tajo y contados los ejemplares de Andalucía y el Sureste. No se han encontrado en el País Valenciano ni en Catahuna (Harrison-Craddock, 1981: 168, fig. 28). Tipológicamente los ejemplares de Formentera se alejan bastante de los tipos del Noroeste, y sus paralelos más exactos se encuentran en el pequeño grupo de hachas del Sureste (hallazgos de Galera, Caniles, Cardenete y Totana), que fueron englobados por Monteagudo en un llamado "tipo Galera" (Monteagudo, 1977: 161). El depósito de este nombre es el que tiene las hachas más parecidas a las nuestras (Schüle, 1969: 20-22).

En resumen nos interesa subrayar que la mayoría de los objetos de bronce considerados tiene probablemente un origen extrainsular. A excepción de las hachas de cubo de tipo balear (con sólo dos ejemplares en las Pitiusas), las demás no parecen ser productos locales, y se puede determinar con cierta seguridad su lugar de procedencia.

\section{CONCLUSIONES}

De este largo repaso de los conocimientos actuales sobre la prehistoria de Ibiza y Formentera se desprende, en primer lugar, la comprobación de que son muy pocos los hechos establecidos y muchas las hipótesis. $\mathrm{Ca} \mathrm{Na}$ Costa, excavada científicamente y con una fecha de $\mathrm{C} 14$ fiable, aparece como el yacimiento-clave a partir del cual se articula buena parte del período. No deja de ser extraño de todas formas que las Pitiusas sean prácticamente las únicas islas del Mediterráneo que no conocen un poblamiento hasta la primera mitad del segundo milenio, cuando las demás se pueblan mucho antes, incluso en el sexto milenio (Córcega) y la misma Mallorca podría haber sido frecuentada en el cuarto milenio (Camps, 1974). No podemos olvidar el dato de que Ibiza es visible numerosos días al año, tanto desde Mallorca como desde la costa alicantina, de las que dista un centenar de kilómetros (Schüle, 1970: fig. 1). 
En cualquier caso existe claramente un Bronce Antiguo, con un sistema de enterramiento megalítico ( $\mathrm{Ca} \mathrm{Na} \mathrm{Costa,} \mathrm{Ca} \mathrm{Sargent)} \mathrm{y} \mathrm{unos} \mathrm{hábitats} \mathrm{en} \mathrm{zonas} \mathrm{llanas} \mathrm{y} \mathrm{sin} \mathrm{aparentes} \mathrm{sistemas}$ defensivos (Cap de Berberia). Este periodo difícilmente podría compararse con el pretalayótico balear, como parecen hacer algunos autores, dadas sus evidentes peculiaridades. Recordemos simplemente que los escasos sepulcros megalíticos conocidos en las islas mayores (Montplé, Alcaidús, Son Bauló de Dalt,...) son difícilmente equiparables a $\mathrm{Ca} \mathrm{Na}$ Costa, a pesar de algunos rasgos comunes que encontramos en numerosas construcciones megaliticas de las más diversas áreas geográficas (Plantalamor, 1978).

Si fechamos en la primera mitad del segundo milenio las cuevas conocidas (Riuets, d'Es Fum, Xives) y las fortificaciones de Sa Cala y Punta Jondal, el claro panorama del Bronce Antiguo se complica un poco. Parecen en efecto poco compatibles grandes hábitats en llano con pequeños grupos humanos viviendo en cuevas, a los que además no podemos suponer desconectados entre sí, al menos en Formentera donde la distancia máxima es de unos $20 \mathrm{~km}$. y donde no existen dificultades orográficas. La imprecisión en nuestro conocimiento de estos últimos yacimientos citados nos impide llegar a una clara conclusión, pero al menos podemos plantear dos hipótesis:

a) existe una sola cultura con diferentes manifestaciones que aún no podemos relacionar, en un mismo periodo; de hecho, las cuevas podrian ser utilizadas ocasionalmente, no como hábitat permanente.

b) el grupo de las cuevas y lugares defensivos es cronológicamente diferenciable del "horizonte $\mathrm{Ca} \mathrm{Na}$ Costan.

Esta segunda posibilidad, que nos parece más lógica pero que no podemos comprobar aún por falta de estudios aceptables, implicaría la existencia de una ocupación de las islas bien en el período 2000-1600 a. J.C., para la cual sólo tenemos de momento los dos fragmentos incisos de la Cova d'Es Fum, bien en el Bronce Medio, en los últimos siglos del segundo milenio, pero sin llegar al Bronce Final (s. IX-VII), ya que no se conocen elementos de contacto con los colonizadores.

Si dejamos de lado la cueva de Es Cuieram, por la escasez de materiales conocidos y su amplia cronología posible, así como el abrigo de Ses Fontanelles, sobre cuya datación ya expresamos serias dudas, sólo nos quedan por valorar los diversos hallazgos de bronces, en especial los depósitos de La Sabina y Can Mariano Gallet. Su cronología, de los siglos VIII-VII y, en especial, los paralelos de las "hachas" de apéndice de Can Mariano Gallet en Alicante, han sugerido que los responsables de la formación y aparición en Formentera de ambos conjuntos pudieron ser los "grupos semitas que según parece fundaron Ebussus a mediados del s. VII a. J.C." (Delibes-Fernández-Miranda, 1984: 1011). Tal hipótesis nos parece plenamente aceptable, y se vería reforzada además por el lugar de origen probable de la mayoría de los elementos de bronce, incluidos los ejemplares de Ses Salines y Sa Bassa Rotja: Sureste peninsular, Midi francés y tal vez Cerdeña (al menos el lingote). Estas coordenadas geográficas corresponden bien con la idea de un origen meridional para los primeros fenicios que frecuentaron y luego se instalaron en Ibiza, dentro de un movimiento de expansión comercial que se desarrolla a lo largo de la costa mediterránea peninsular hasta llegar al sur de Francia.

Todo ello no nos debe hacer descartar la posibilidad de la existencia de algunos grupos humanos en las Pitiusas en los s. VIII-VII a. J.C. Ya hemos visto cómo en los últimos años la idea de un despoblamiento de las islas antes de los fenicios se ha desmoronado gracias a la investigación y a las excavaciones, y no se puede ser tajante en estos problemas en los que un trabajo de campo más intenso puede dar grandes sorpresas. Sin embargo, creemos que la situación actual de la investigación permite hacer una serie de reflexiones.

No existe en ninguna de las dos islas yacimiento indígena alguno fechable en el s. VII a. J.C., que, como veremos, es el de la instalación de los fenicios en Ibiza. No sólo no tenemos tumbas, santuarios, hábitats, etc...: es que simplemente no existe hoy por hoy ningún elemento material que nos hable de esa teórica cultura isleña, no hay cerámicas, objetos de metal... Incluso los escasos objetos de bronce, las hachas especialmente, que hemos revisado apuntan más a las relaciones comerciales de los fenicios en la zona mediterránea occidental que a las actividades de isleños en la 
Edad del Bronce. Precisando más hay que decir que las escasas cerámicas a mano recogidas en las excavaciones metódicas del Puig des Molins corresponden claramente bien a modelos fenicios bien a cerámicas talayóticas mallorquinas y menorquinas. Estas últimas nos hablan de contactos fenicios con las Baleares mayores, atestiguados ya sin ningún género de dudas en el s. VI a. J.C. (Guerrero, 1984: 9-17), pero difícilmente pueden servir para plantear la existencia de un talayótico ibicenco.

En resumen, el panorama de la prehistoria es, para nosotros, de momento el siguiente: un Bronce Antiguo claramente atestiguado, un posible pero dudoso Bronce Medio y un vacío de varios siglos, al menos desde finales del segundo milenio hasta el s. VII a. J.C. A este respecto queremos subrayar que ese vacío no debe parecer un fenómeno totalmente anómalo. Estudiando el poblamiento inicial de las islas mediterráneas en su conjunto, J. Cherry ha mostrado en efecto que no son excepcionales los casos en que un vacío cronológico corresponde realmente a una ausencia de población: así puede comprobarse la recolonización de Chipre en el cuarto milenio, tras una fase neolítica notable en el sexto milenio y un hiato de casi mil años. Semejante situación se produce en varias islas de las Cícladas (Astipalea, etc., ...) e incluso Creta conoce la casi extinción de su población en el neolítico inicial y medio. Como expone el mencionado autor refiriéndose a aquellos lugares poblados por grupos demográficos muy restringidos y relativamente aislados, como podemos pensar que eran los de Ibiza y Formentera en el segundo milenio, "the material consequences of such small-group demographic processes in strictly bounded, impredictable environments are likely to be very slow growth in population numbers and local extinctions, producing breaks in the archaelogical sequence" (Cherry, 1981: 60-61).

Creemos, pues, que cabe pensar que en el área que nos afecta se produjo una ruptura en la secuencia cultural, y otros investigadores están empezando a tomar también en cuenta las ideas de Cherry sobre extinciones puntuales de población en las Baleares (Chapman, 1985: 146-147). Evidentemente los ejemplos que hemos mencionado se refieren a períodos muy anteriores al que aquí tratamos, y podría parecer extraño que a fines de la Edad del Bronce las Pitiusas estuvieran despobladas. ¿Pero acaso la misma Formentera no estuvo totalmente deshabitada durante trescientos años en época bien reciente, entre los s. XIV y XVII (Macabich, 1952, 574 y ss.; Marí Cardona, 1983: 9 y ss.)? Para nosotros esta ausencia de población (o, dejando la puerta abierta al futuro, la escasa entidad numérica y cultural de los pobladores) en los s. VIII y VII a. J.C. fue uno de los factores que favorecieron la instalación de una factoría fenicia en Ibiza. A su vez, esta falta de sustrato indígena condicionará muy peculiarmente el desarrollo colonial de la isla; es el único lugar del Mediterráneo en el que los fenicios se asientan con entera libertad de acción y en el que su posterior evolución social y cultural no depende de sus relaciones con la población autóctona, como en Chipre, Malta, Sicilia, Cerdeña o cualquier otro lugar.

\section{BIBLIOGRAFIA}

Almagro Basch, M. (1960): Manual de Historia Universal, t. I. Espasa-Calpe. Madrid.

- (1962): «Inventaria Archaeologica». Madrid, fasc. 6.

- (1967): «Inventaria Archaeologica». Madrid, fasc. 7.

Almagro Gorbea, M. J.; FortunY, E. DE (1971): «Excavaciones en la Cueva de Es Cuyeram (Ibiza)». Noticiario Arqueológico Hispánico, XIII-XIV: 7-35.

AuBET, M. E. (1968): «La Cueva d'es Cuyram (Ibiza)». Pyrenae, 4: 1-66.

- (1982): El santuario de Es Cuieram. Trabajos del Museo Arqueológico de Ibiza, 8. Ibiza.

BARRoso RuIz, C. (1980): «Nuevas pinturas rupestres en Jimena de la Frontera (Cádiz): Abrigo de Laja Alta». Zephyrus, XXX-XXXI: 23-42.

Bisi, A. M.; Guzzo AmadASI, M. G., y TuSA, V. (1969): Grotta Regina-I. Coll. Studi Semitici, 33. Roma.

BLANCE, B. (1971): «Die Anfange der Metallurgie auf der Iberischen Halbinseb. Studien zu den Anfängen der Metallurgie, 4. Berlín.

BreUIL. H. (1920): «Cueva de las Fontanellas (Iviça)». Boletín de la Real Sociedad Española de Historia Natural, $\mathrm{XX}, 10$.

CAMPS, G. (1974): La question des navigations préhistoriques dans le bassin occidental de la Mediterranée. 
Travaux du Laboratoire d'Anthropologie de Préhistoire et d'Ethnologie des Pays de la Méditerranée Occidentale, Univ. de Provence. Aix.

Cantarellas Camps. C. (1972): Cerámica incisa en Mallorca. Ed. Caja de Ahorros y Monte de Piedad de las Baleares. Palma de Mallorca.

Coacci Polselu. G.; Guzzo Amadasi, M. G., y Tusa, V. (1979): Grotta Regina-II. Coll. Studi Semitici, 52. Roma.

Chapman. R. W. (1985): "The Later Prehistory of Western Mediterranean Europe: Recent Advance». Advances in World Archaeology, 4 (Academic Press): 115-187.

Chardenoux. M. B.; Courtols. J. C. (1979): Les haches dans la France Méridionale. Prähistorische Bronzefunde IX, 11. Munich.

Cherry. J. F. (1981): „Pattern and process in the Earliest Colonisation of the Mediterranean Islands». Proceedings of the Prehistoric Society, 47: 41-68.

CHILDE, V. G. (1957): The Dawn of European Civilization. Routhledge and Kegan Paul. Londres.

DANIEL G. (1958): The Megalith Builders of Western Europa. Hutchinson. Londres.

Delibes de Castro, G.; Fernandez-Miranda. M. (1984): "Metalurgia balear de la Edad del Bronce: hachas de cubo, de talón, de apéndices laterales». Conferencia de Deyá. B.A.R., 229, III (Oxford): 998-1025.

Fernández, J. H. (1973): «Nuevo depósito de hachas de bronce descubierto en la isla de Formentera». Pyrenae, 9: $177-183$.

- (1974): «Hachas de bronce halladas en Ibiza y Formentera». VI Symposium de Prehistoria Peninsular (Barcelona 1972): 64-71.

- (1977): «Ultimos descubrimientos prehistóricos de la isla de Formenteran. Actas del XIV Congreso Nacional de Arqueologia (Vitoria, 1975): 471-477.

- (1984): «The Prehistory of Eivissa and Formentera». En H. Kuhbier, J. A. Alcover y C. Guerán de Arellano (Eds.): «Biogeography and ecology of the Pityusic Islands*. Dr. W. Junk Publ. La Haya: 565-595.

Fernández, J. H.; Plantalamor, L., y TOPP, C. (1976): "Excavaciones en el sepulcro megalítico de Ca Na Costa (Formentera)». Estudios de Prehistoria Balear, 1 (Separata de Mayurqa, 15): 101-138.

Fernández, J. H.; TOPP, C. (1984): "Prehistoric activities in the Pitiussae Islands». Deyá Conference of Prehistory, B.A.R., 229 (Oxford): 763-784.

Fernández-Miranda, M. (1978): Secuencia cultural de la prehistoria de Mallorca Biblioteca Praehistorica Hispana, XV. Madrid.

Garcia y Bellido, A. (1952): «Colonización púnica». En R. Menéndez Pidal (Dir.): «Historia de España», I, II. Espasa-Calpe. Madrid: 309-492.

GonzÁlez Prats, A. (1982): «Peña Negra IV. Excavaciones en el Sector VII de la ciudad orientalizante (19801981)m. Noticiario Arqueológico Hispánico, 13: 305-418.

- (1986): «Sobre unos elementos materiales del comercio fenicio en tierras del Sudeste Peninsular». Lucentum, IV: $97-106$.

GordIL COURCIERES, J. L. (1981): Formentera, historia de una isla. Albatros Ediciones. Valencia

Guerrero Ayuso, V. M. (1984): La colonización púnico-ebusitana de Mallorca. Estado de la cuestión. Trabajos del Museo Arqueológico de Ibiza, 11. Ibiza.

Hardaker, R. (1976): «Las hachas de cubo de la Península Ibérica*. Cuadernos de Prehistoria y Arqueologia Castellonense, 3: 151-171.

HaRrison, R. J.; CRADDOCK, P. T. (1981): «A study of the Bronze Age Metalwork from the Iberian Peninsula in the British Museumm. Ampurias, 43: 113-179.

LERMA. J. V. (1981): "Los origenes de la metalurgia en el País Valenciano». Archivo de Prehistoria Levantina, XVI: $129-140$.

LuLL, V. (1983): La «cultura de El Argar. E. Akal, Col. Universitaria, 49. Madrid.

MaCABICH, I. (1966): Historia de Ibiza, vol. I. Edit. Daedalus. Palma de Mallorca.

Maluquer, J.; GIRO, P.; MAssachs, J. M. (1963): Excavaciones en sepulcros megaliticos de Valldossera (Querol, Tarragona). Excavaciones Arqueológicas en España, 20. Madrid.

Maña de Angulo, J. M. (1952): "Notas arqueológicas sobre Formentera». Memorias de los Museos Arqueológicos Provinciales, XIII: 12-16.

Mari Cardona, J. (1983): Illes Pitiuses: III. Formentera. Institut d'Estudis Eivissencs. Ibiza.

MARI TUR, J. (1973): «Nuevo testimonio de la Edad de Bronce en Ibiza». Eivissa, 1: 7-8.

MARTI JUSMeT, F. (1970): «Las hachas de bronce en Cataluñan. Ampurias, 31-32: 105-151.

Mestres, J. (1982): «Mas Plá (Valldosera, Querol)». Las excavaciones arqueológiques a Catalunya en els darrers anys, Generalitat de Catalunya: 119-120.

Monteagudo, L. (1977): Die Beile auf der Iberischen Halbinsel Prăhistorische Bronzefunde IX, 6. Munich.

Pérez Cabrero, A. (1909): Ibiza. Guía del turista. Imprenta de J. Costa. Barcelona.

- (1911): Ibiza arqueológica. Est. gráfico Thomás. Barcelona.

Plantalamor Massanet, L (1978): *Algunas consideraciones sobre los sepulcros megalíticos de Menorcan. Sautuola, II: 157-173.

RAMON TORReS, J. (1985a): Els monuments antics de les Illes Pitiuses. Conselleria de Cultura. Consell Insular d'Eivissa i Formentera. Ibiza.

- (1985b): «Es Cuieram 1981». Noticiario Arqueológico Hispánico, 20: 225-256. 
Román Ferrer. C. (1913): Antigüedades Ebusitanas. Tip. La Académica. Barcelona.

ROSELLó BORDOY, G. (1974): «Los ajuares metálicos mallorquines como elemento cronológicon. VI Symposium de Prehistoria Peninsular (Barcelona, 1972): 115-127.

Schubart. H. (1975): Die Kultur der Bronzezeit im Südwesten der Iberischen Halbinsel. Madrider Forschungen, 9. Berlin.

SCHULE, W. (1969): Die Meseta-Kulturen der Iberischen Halbinsel. Madrider Forschungen, 3. Berlin.

- (1970): «Navegación primitiva y visibilidad de la tierra en el Mediterráneo». Actas del XI Congreso Nacional de Arqueología (Mérida, 1968): 449-462.

SORA BONED, M. (1944): «Restos de la Edad del Bronce en Ibiza y Formentera». Rev. Ibiza (1.a época) 2: 18-20.

TARRADELL, M.; Font, M. (1975): Eivissa Cartaginesa. Bibl. de Cultura Catalana, 13. Ed. Curial. Barcelona

TOPP. C.; FernánDEZ, J. H., y PlantalamoR, L. (1976): «Ca Na Costa: a Megalithic chamber tomb on Formentera, Balearic Islandsw. Bulletin, 13. Institute of Archaeology of the University of London: 139-174.

- (1979): «Recent archaeological activities in Ibiza and Formentera». Bulletin, 13. Institute of Archaeology of the University of London: 215-231.

TRIAS, M.; ROCA, LL. (1975): «Noves aportacions al coneixement de les coves de Sa Mola (Formentera) i de la seva importancia arqueologican. Endins, 2: 15-33.

TRIAS, M. (1977): «Cova Xives: troballes prehistoriques a Eivissaw. Endins, 4: 49-52.

VENY, C. (1968): Las cuevas sepulcrales del Bronce Antiguo de Mallorca. Biblioteca Praehistorica Hispana, IX. Madrid.

VIVES Y Escudero, A. (1917): Estudio de Arqueología Cartaginesa. La necrópoli de Ibiza. Imprenta de Blass y Cía. Madrid.

WALDREN,W. (1985): Balearic Beaker wares, an inventory. Damarc. Deyà. 


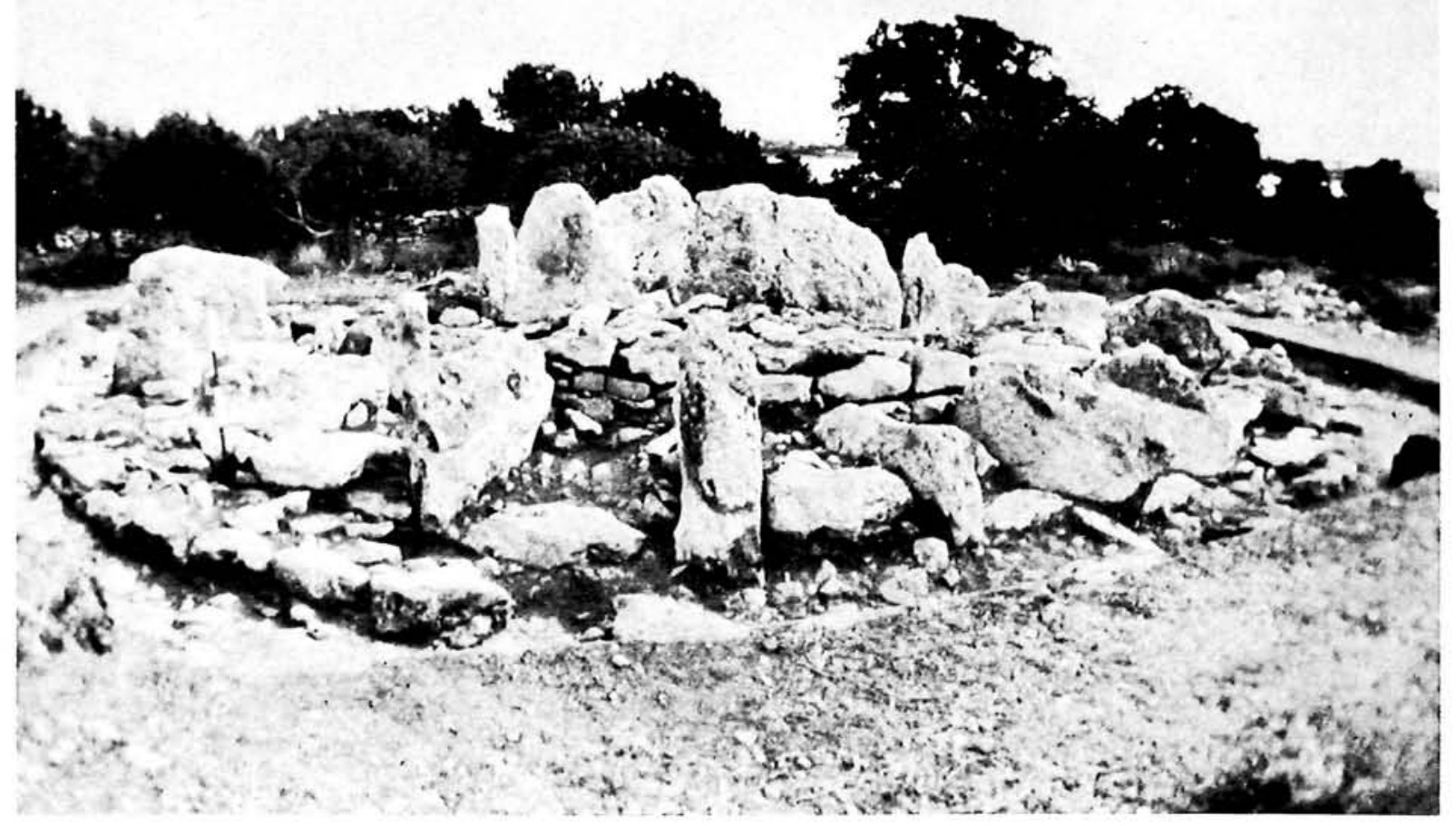

a.- Sepulcro megalítico de Ca Na Costa, Formentera (Foto M.A.I.).

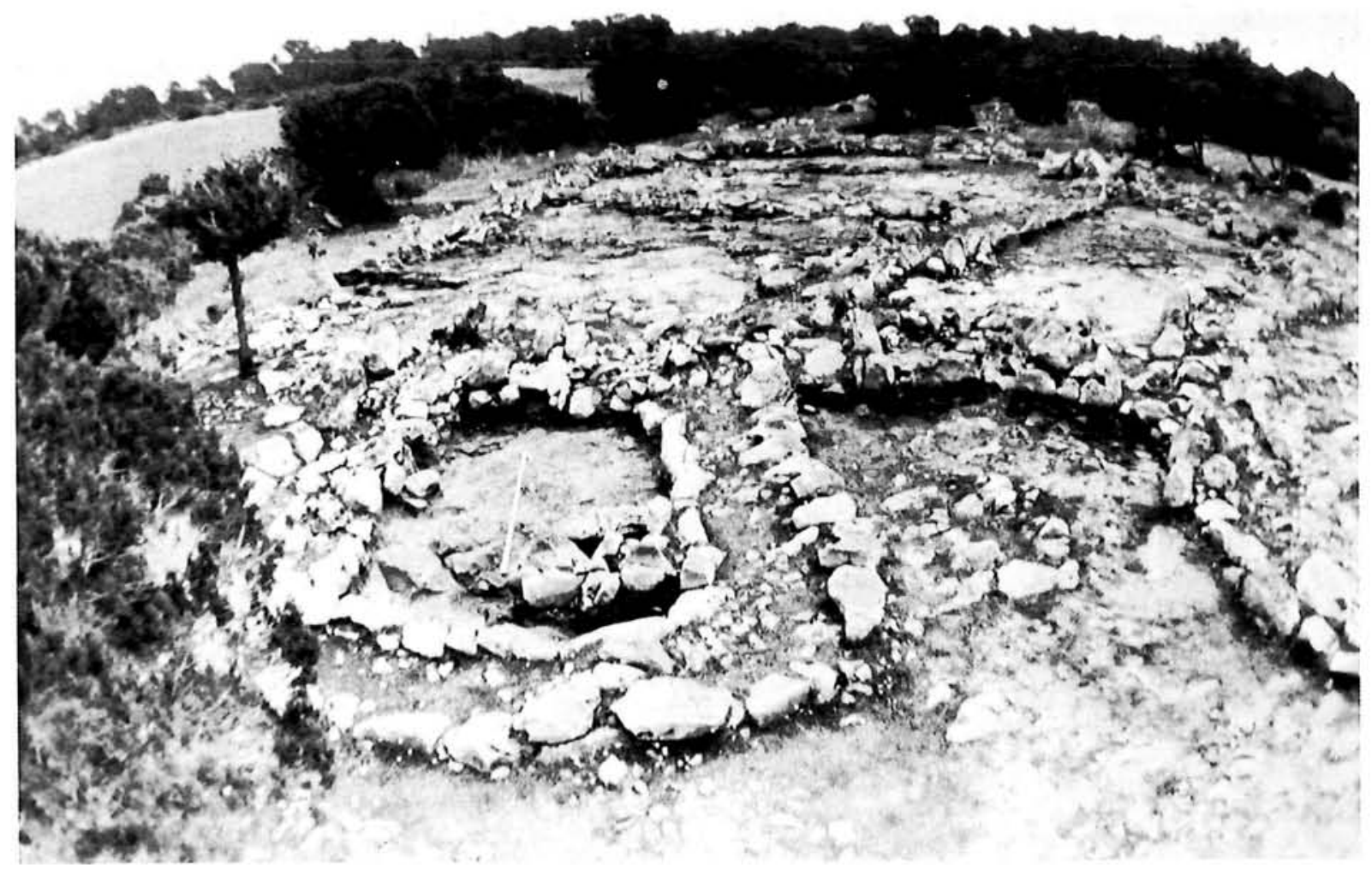

b.- Vista parcial del hábitat del Cap de Berbería, Formentera, desde el N.O. (Foto cortesía de B. Costa Ribas). 


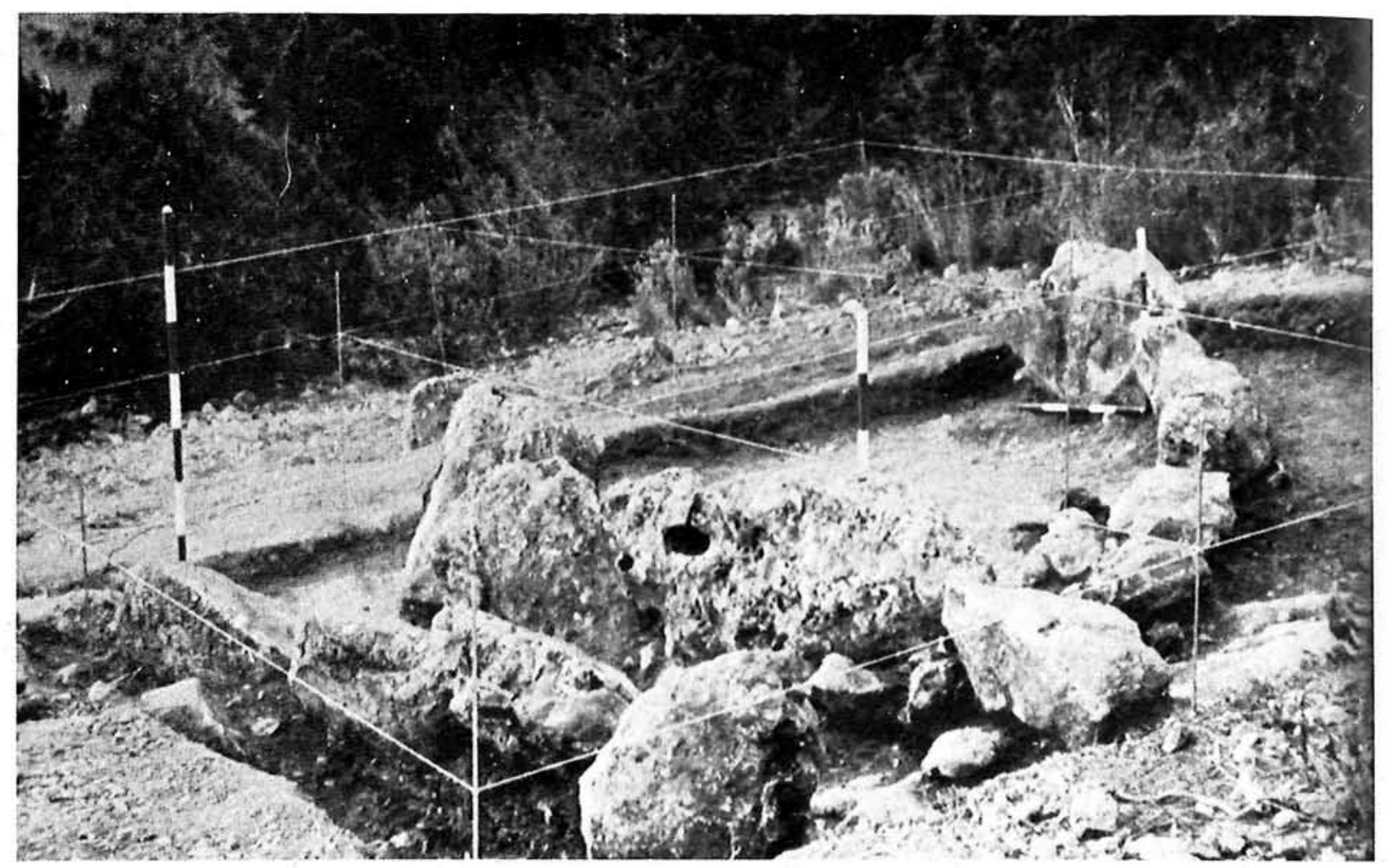

a.-Vista del sepulcro megalítico de Can Sargent I, Ibiza, desde el N. (según C. Topp et alii, 1979).
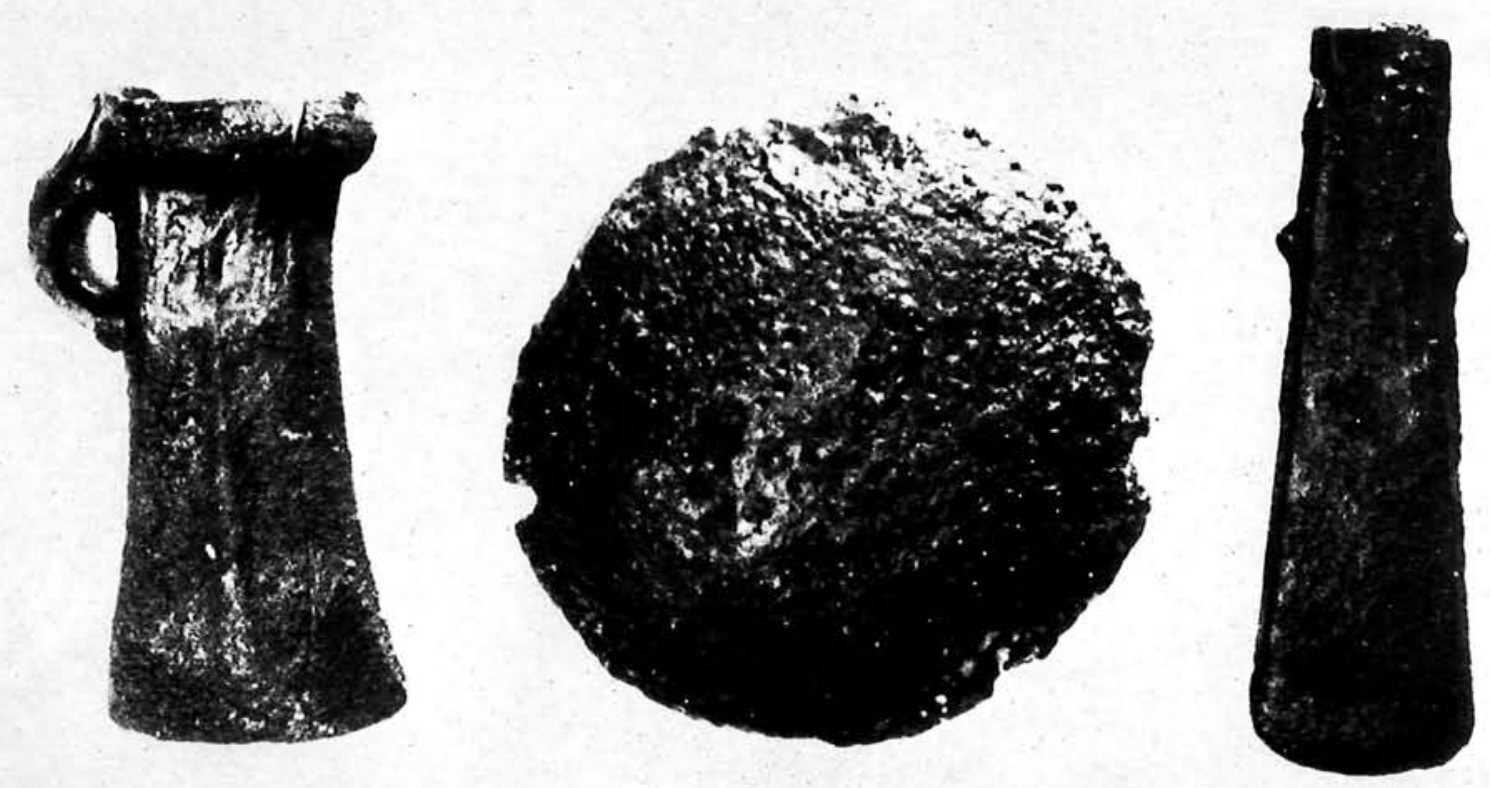

b.-Depósito de bronce de La Sabina, Formentera. (Foto M.A.I.). 